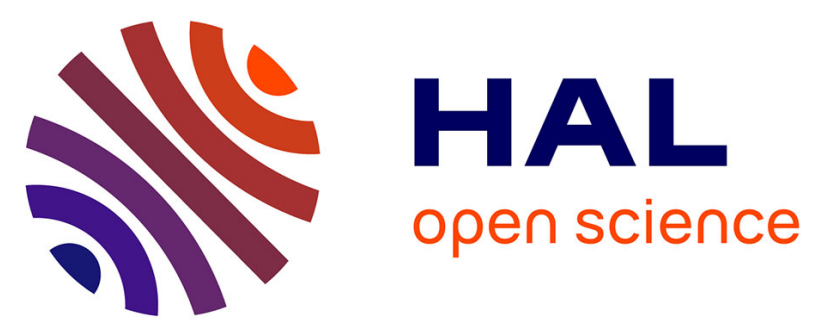

\title{
Pathological modeling of TBEV infection reveals differential innate immune responses in human neurons and astrocytes that correlate with their susceptibility to infection
}

\author{
Mazigh Fares, Marielle Cochet-Bernoin, Gaëlle Gonzalez, Claudia \\ Montero-Menei, Odile Blanchet, Alexandra Benchoua, Claire Boissart, Sylvie \\ Lecollinet, Jennifer Richardson, Nadia Haddad, et al.
}

\section{- To cite this version:}

Mazigh Fares, Marielle Cochet-Bernoin, Gaëlle Gonzalez, Claudia Montero-Menei, Odile Blanchet, et al.. Pathological modeling of TBEV infection reveals differential innate immune responses in human neurons and astrocytes that correlate with their susceptibility to infection. Journal of Neuroinflammation, 2020, 17 (1), pp.76. 10.1186/s12974-020-01756-x . inserm-02914090

\section{HAL Id: inserm-02914090 https://www.hal.inserm.fr/inserm-02914090}

Submitted on 11 Aug 2020

HAL is a multi-disciplinary open access archive for the deposit and dissemination of scientific research documents, whether they are published or not. The documents may come from teaching and research institutions in France or abroad, or from public or private research centers.
L'archive ouverte pluridisciplinaire HAL, est destinée au dépôt et à la diffusion de documents scientifiques de niveau recherche, publiés ou non, émanant des établissements d'enseignement et de recherche français ou étrangers, des laboratoires publics ou privés. 


\title{
RESEARCH
}

Open Access

\section{Pathological modeling of TBEV infection reveals differential innate immune responses in human neurons and astrocytes that correlate with their susceptibility to infection}

Mazigh Fares ${ }^{1,2}$, Marielle Cochet-Bernoin', Gaëlle Gonzalez ${ }^{1}$, Claudia N. Montero-Menei ${ }^{3}$, Odile Blanchet ${ }^{4}$, Alexandra Benchoua ${ }^{5}$, Claire Boissart ${ }^{5}$, Sylvie Lecollinet ${ }^{1}$, Jennifer Richardson ${ }^{1}$, Nadia Haddad ${ }^{6}$ and Muriel Coulpier ${ }^{1 *}$ (i)

\begin{abstract}
Background: Tick-borne encephalitis virus (TBEV) is a member of the Flaviviridae family, Flavivirus genus, which includes several important human pathogens. It is responsible for neurological symptoms that may cause permanent disability or death, and, from a medical point of view, is the major arbovirus in Central/Northern Europe and North-Eastern Asia. TBEV tropism is critical for neuropathogenesis, yet little is known about the molecular mechanisms that govern the susceptibility of human brain cells to the virus. In this study, we sought to establish and characterize a new in vitro model of TBEV infection in the human brain and to decipher cell type-specific innate immunity and its relation to TBEV tropism and neuropathogenesis.

Method: Human neuronal/glial cells were differentiated from neural progenitor cells and infected with the TBEV-Hypr strain. Kinetics of infection, cellular tropism, and cellular responses, including innate immune responses, were characterized by measuring viral genome and viral titer, performing immunofluorescence, enumerating the different cellular types, and determining their rate of infection and by performing PCR array and QRT-PCR. The specific response of neurons and astrocytes was analyzed using the same approaches after enrichment of the neuronal/glial cultures for each cellular subtype.

Results: We showed that infection of human neuronal/glial cells mimicked three major hallmarks of TBEV infection in the human brain, namely, preferential neuronal tropism, neuronal death, and astrogliosis. We further showed that these cells conserved their capacity to mount an antiviral response against TBEV. TBEV-infected neuronal/glial cells, therefore, represented a highly relevant pathological model. By enriching the cultures for either neurons or astrocytes, we further demonstrated qualitative and quantitative differential innate immune responses in the two cell types that correlated with their particular susceptibility to TBEV.

(Continued on next page)
\end{abstract}

\footnotetext{
* Correspondence: muriel.coulpier@vet-alfort.fr

'UMR1 161 Virologie, Anses, INRAE, Ecole Nationale Vétérinaire d'Alfort, Université Paris-Est, Maisons-Alfort, France

Full list of author information is available at the end of the article
}

(c) The Author(s). 2020 Open Access This article is licensed under a Creative Commons Attribution 4.0 International License, which permits use, sharing, adaptation, distribution and reproduction in any medium or format, as long as you give appropriate credit to the original author(s) and the source, provide a link to the Creative Commons licence, and indicate if changes were made. The images or other third party material in this article are included in the article's Creative Commons licence, unless indicated otherwise in a credit line to the material. If material is not included in the article's Creative Commons licence and your intended use is not permitted by statutory regulation or exceeds the permitted use, you will need to obtain permission directly from the copyright holder. To view a copy of this licence, visit http://creativecommons.org/licenses/by/4.0/ The Creative Commons Public Domain Dedication waiver (http://creativecommons.org/publicdomain/zero/1.0/) applies to the data made available in this article, unless otherwise stated in a credit line to the data. 
(Continued from previous page)

Conclusion: Our results thus reveal that cell type-specific innate immunity is likely to contribute to shaping TBEV tropism for human brain cells. They describe a new in vitro model for in-depth study of TBEV-induced neuropathogenesis and improve our understanding of the mechanisms by which neurotropic viruses target and damage human brain cells.

Keywords: Neurotropic virus, Flavivirus, Tick-borne encephalitis virus, Central nervous system, Human neuronal/glial cells, Viral tropism, Innate immunity, Neuropathogenesis, Pathological modeling

\section{Background}

Tick-borne encephalitis virus (TBEV) belongs to the genus Flavivirus (family Flaviviridae), whose members include several important human pathogens transmitted by arthropods, such as Japanese encephalitis virus (JEV), West Nile virus (WNV), Zika virus (ZIKV), and Powassan virus (POWV). From a medical point of view, TBEV is the most important arbovirus in Europe and NorthEastern Asia. Its endemic zone spreads from Northern, Central, and Eastern Europe to Far East Asia [1]. It induces a range of symptoms from mild flu-like symptoms to severe encephalitis and paralysis, often with long-term neurological sequelae [2]. The incidence of the disease has increased in recent decades, and autochthonous cases are regularly reported in new areas of Western Europe, reflecting an expansion to non-endemic areas [3]. Despite commercialization of an effective vaccine [4], between 8000 and 13,000 annual cases of tick-borne encephalitis have been reported worldwide since the 1990s [5]. No therapy is currently available [6].

TBEV is usually transmitted to humans from infected ticks, mainly of the Ixodes family, but may occasionally be acquired by consumption of unpasteurized dairy products from infected livestock [7-9]. Upon inoculation into the human skin, initial infection and replication occur in local dendritic cells (DCs). DCs are believed to transport the virus to draining lymph nodes from which it spreads into the bloodstream and induces viremia. It may then cross the blood-brain barrier and cause widespread lesions in the brain. These include inflammatory changes, neuronal damage, and glial reactivity in several brain areas, including the spinal cord, brainstem, cerebellum, and striatum [10, 11]. Neurons are the primary target of infection [12], but other cells in the central nervous system (CNS) may contribute to TBEV-induced neuropathogenesis. Both infiltrating immunocompetent cells, mainly $\mathrm{CD}^{+} \mathrm{T}$ cells, and resident glial cells, such as astrocytes and microglial cells, have been shown to play a role $[13,14]$. Neuronal damage may thus be mediated directly by viral infection or indirectly by infiltrating immunocompetent cells, inflammatory cytokines, and activated resident glial cells.

The innate immune response is the first line of defense against viral infection. Type I interferons (IFNs) are of particular importance in this process. Through binding to the IFN alpha/beta receptor (IFNAR), they act via autocrine or paracrine signaling [15-17] and trigger the activation of a large number of interferon-stimulated genes (ISGs) that can inhibit almost every step of the viral life cycle [18]. In recent years, it has become clear that parenchymal cells of the CNS play a major role in the development of the innate immune response and the protection of infected individuals after CNS infection [19-24]. Neurons and astrocytes are not passive targets, as they are known to produce and respond to type I IFNs. Nevertheless, the innate immune programs activated in these cell types during TBEV infection and their impact on viral tropism and neuropathogenesis remain poorly known.

Animal models have been widely used to elucidate the cellular and molecular mechanisms of TBEV-induced neuropathogenesis [2]. Nevertheless, the results obtained from such studies may be difficult to transpose to human neuropathogenesis, as human antiviral responses differ substantially from those of other mammalian species $[25,26]$. The biological relevance of models based on human CNS cells is thus increasingly recognized. These include neuronal/glial cell lines, primary neuronal/glial cells from human fetuses, and more recently, neuronal/glial cells derived from fetal neural progenitors (hNPCs), embryonic (hESCs), or induced pluripotent stem cells (hiPSCs). While primary human CNS cells are physiologically more relevant than cell lines, their use is limited by the difficulty in gaining access to cell sources. On the other hand, neuronal/glial cultures derived from neural progenitors are not only physiologically relevant, but also have the advantage of being available on demand. In recent years, they have become important tools to study neurotropic viruses [27].

The goal of this study was, first, to set up and characterize a new in vitro model of TBEV infection using complex co-cultures of hNPC-derived neuronal/ glial cells and, second, to decipher cell-specific antiTBEV immunity in the human CNS and its relation to TBEV tropism and neuropathogenesis. We showed that in vitro TBEV infection mimics several hallmarks of in vivo infection, including marked neuronal tropism and neuronal death, limited astrocyte susceptibility, astrogliosis, and induction of an antiviral response. Moreover, we demonstrated differential qualitative and 
quantitative antiviral capacities in human neurons and astrocytes that are correlated with their susceptibility to TBEV infection. Finally, we showed that human astrocytes exert a protective effect on neighboring TBEVinfected neurons.

\section{Methods}

\section{Ethics statement}

Human fetuses were obtained after legal abortion with written informed consent from the patient. The procedure for the procurement and use of human fetal central nervous system tissue was approved and monitored by the "Comité Consultatif de Protection des Personnes dans la Recherche Biomédicale" of Henri Mondor Hospital, France. The cells are declared at the "Centre de Ressources Biologiques" of the University Hospital in Angers BB-0033-00038 with reference numbers at the Research Ministry: declaration no. DC-2011-1467 and authorization no. AC-2012-1507.

The rabbit immunization protocol complied with EU legislation (authorization 12/04/11-6 given by the ANSES/ENVA/UPEC ethical committee).

\section{Culture of human neural progenitor cells}

Human neural progenitor cells (hNPCs) were prepared and cultured as previously described in [28, 29]. They are self-renewing cells and therefore may provide an unlimited source of material.

\section{Neuronal and glial differentiation}

hNPCs were seeded on matrigel-coated plates at a density of 30,000 cells $/ \mathrm{cm}^{2}$. Differentiation into a mixed population of neuronal and glial cells was induced $24 \mathrm{~h}$ after plating by replacing N2A medium with 1:1 N2A and NBC media (N2A: advanced Dulbecco's modified Eagle medium-F12 supplemented with $2 \mathrm{mML}$-glutamine, $0.1 \mathrm{mg} / \mathrm{ml}$ apotransferrin, $25 \mu \mathrm{g} / \mathrm{ml}$ insulin, and 6.3 $\mathrm{ng} / \mathrm{ml}$ progesterone; NBC: neurobasal medium supplemented with $2 \mathrm{mML}$-glutamine and B27 without vitamin A 1X-Invitrogen, Life Technologies) and withdrawing EGF (TEBU, France) and bFGF (TEBU, France). Differentiation conditions were maintained for 13 days with medium replacement twice a week, prior to infection. Twenty-four-well plates (IBIDI, \#82406) were used for fluorescent immunostaining, and 6-well plates (Falcon) were used to prepare lysates for RNA analyses.

\section{Virus and infection}

TBEV-Hypr strain was a kind gift from Dr. S. Moutailler (Maisons-Alfort, France). The strain was isolated in 1953 from the blood of a 10-year-old child in the Czech Republic, and the complete sequence was published in [30]. A working stock was generated in VERO cells (VERO-ATCC-CCL81) cultured in MEM medium
(ThermoFisher) supplemented with $2 \%$ fetal bovine serum (FBS). Titer was estimated by plaque assay on VERO cells. Neuronal/glial cells differentiated for 13 days were infected with the virus (MOI $10^{-2}$ ) for $1 \mathrm{~h}$ at $37^{\circ} \mathrm{C}$. The inoculum was removed and cells were incubated in fresh N2A-NBC medium. Virus titers were estimated by endpoint dilution on VERO cells (TCID50). All procedures with infectious materials were performed under bio-safety level-3 (BSL-3) conditions.

\section{RNA isolation and qPCR}

RNA was isolated from infected and non-infected neuronal/glial co-cultures. Cells were lysed using the Nucleo$M a g^{\circ} 96$ RNA kit (Macherey Nagel), and RNA was extracted with a King Fisher Duo automat (Fisher Scientific) following the manufacturer's instructions. Extraction of viral RNA from supernatants of infected cells was performed using QIAamp Viral RNA Mini Kit (Qiagen) according to the manufacturer's instructions. One hundred and sixty nanograms (Fig. 5) or $250 \mathrm{ng}$ (Figs. 7 and 1d) of RNA from cell lysates and $2 \mu \mathrm{l}$ of RNA from supernatant (Fig. 1d) were used to synthesize cDNA with the SuperScript ${ }^{\text {th }}$ II Reverse Transcriptase kit (ThermoFisher Scientific). Real-time PCR was performed using $2 \mu \mathrm{l}$ of cDNA and QuantiTect SYBR green PCR master (Qiagen) with a LightCycler 96 instrument (Roche Applied Science), for a total volume of $20 \mu \mathrm{l}$ of reaction mixture. For relative quantification, the $-2 \Delta \Delta \mathrm{Ct}$ method was used [31]. The reference genes were GAPDH or HPRT1. Primers pairs are listed in Additional file 1. TBEV primers pairs were from Schwaiger et al. [32].

\section{$\mathrm{RT}^{2}$ profiler PCR array}

Equal volumes of RNA from biological triplicates were pooled for each condition. Two hundred to $500 \mathrm{ng}$ of RNA were transcribed with the $R T^{2}$ First Strand Kit (SA Biosciences, Qiagen). Synthetized cDNA was subjected to a PCR array specific for the human antiviral response ( $R T^{2}$ Profiler PCR array-PAHS-122Z, SA Biosciences, Qiagen), according to the manufacturer's instructions. Data were normalized using the HPRT1 house-keeping gene and analyzed with the $-2 \Delta \Delta \mathrm{Ct}$ method for relative quantification. According to the manufacturer's instructions, an arbitrary cut-off of 3 was applied to determine significant differences. The analysis was performed using the Qiagen Data analysis center (http://www.qiagen. $\mathrm{com} / \mathrm{fr} / \mathrm{shop} /$ genes-and-pathways/data-analysis-centeroverview-page/).

\section{Immunofluorescence assays and cell enumeration}

Neuronal/glial cells were fixed for $20 \mathrm{~min}$ in $4 \%$ paraformaldehyde in PBS (Electron Microscopy Sciences) and standard immunofluorescence was performed using antibodies for $\mathrm{HuC} / \mathrm{HuD}$ (Thermofisher \#A21271), BIII- 
(A)

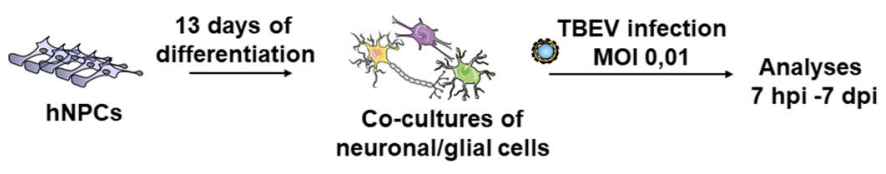

(B)

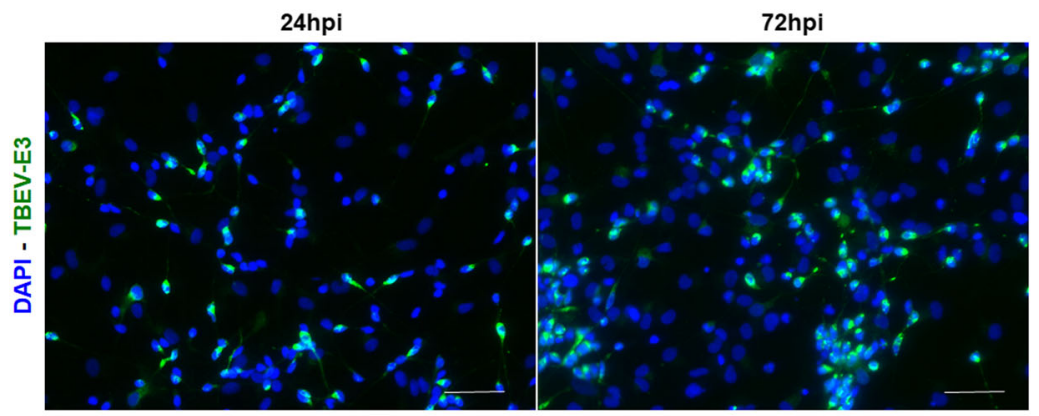

(C)

(D)

(E)
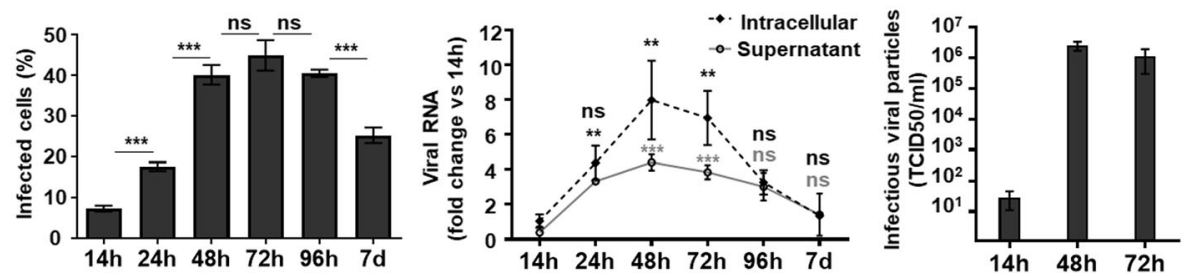

Fig. 1 TBEV infects, replicates, and spreads in hNPC-derived brain cells. a Schematic representation of the experimental procedure. $\mathbf{b}$ Immunofluorescence labeling of differentiated hNPCs $24 \mathrm{~h}$ and $72 \mathrm{~h}$ following TBEV infection. An antibody directed against the domain 3 of the viral envelope (TBEV-E3, green) revealed infected cells. Nuclei were stained with DAPI (blue). c Enumeration of infected cells based on immunofluorescence labeling using an ArrayScan Cellomics instrument. d RNA from the supernatant and cell lysate of infected cells was analyzed by RT-qPCR to determine viral replication. e Supernatant was collected at 14, 48, and 72 hpi and titrated by endpoint dilution (TCID50) on VERO cells. Results are representative of 3 independent experiments performed in triplicate. Data are expressed as the mean \pm SD. Statistical analysis was performed using one-way ANOVA (Bonferroni's Multiple Comparison Test) with Graphpad Prism V6.0.1. ns, non-significant $(p>0.05) ;{ }^{* *} p<$ $0.01,{ }^{* * *} p<0.001$. Scale bar $=100 \mu \mathrm{m}$

tubulin (Sigma \#T8660), GFAP (Dako \#M076101-2 or \#Z033429-2), OLIG2 (R\&D Systems \#AF2418), and TBEV-E3. TBEV-E3 antibody was produced as follows: a rabbit polyclonal antiserum was raised against the TBEV E domain 3 after 3 sequential immunizations of 3months old New Zealand rabbits with $100 \mu \mathrm{g}$ of Ni2+resins affinity-purified antigen adjuvanted with ISA50V2 (SEPPIC, France) at a 3-week interval and was collected on week 8 after the prime. The production of affinitypurified TBEV E domain 3 has been detailed in Beck et al. [33]. Cells were blocked for $1 \mathrm{~h}$ in $3 \%$ BSA (Sigma), $0.3 \%$ Triton-X-100 (VWR) in PBS $1 \mathrm{X}$ and primary antibodies were diluted in $1 \%$ BSA, $0.1 \%$ Triton-X-100 in PBS 1X, and incubated overnight at $+4{ }^{\circ} \mathrm{C}$. Secondary antibodies were Alexa Fluor-488/546-conjugated antimouse/anti-rabbit IgG (Molecular Probes, Invitrogen). Nuclei were stained with 4',6-diamidino-2-phenylindole (DAPI) (Life Technologies) at $0.1 \mathrm{ng} / \mathrm{ml}$. For the assessment of apoptotic cell death, terminal deoxynucleotidyltransferase-mediated dUTP-biotin nick end labeling (TUNEL) staining was performed according to the manufacturer's instructions (Promega, France). Cell sub-types and infected cells were enumerated either manually or automatically. For manual cell quantification (cells immunostained with antibodies directed against BIII-tubulin and GFAP), images were acquired with an AxioObserver Z1 (Zeiss) inverted microscope using ZEN software (Zeiss) and analyzed using ImageJ $1.49 \mathrm{~m}$ software. For automated quantification (cells immunostained with antibodies directed against $\mathrm{HuC} /$ $\mathrm{HuD}$, TBEV-E3 and OLIG2, neurites immunostained with an antibody against BIII-tubulin- and TUNELstained cells), images were acquired using the Cellomics ArrayScan automated microscope (Thermofisher Scientific) and analyzed using "Colocalization" or "Neuronal profiling" bio-applications on HCS Studio Cell Analysis Software V6.6.0 (Thermofisher Scientific). In all experiments, an average of 1200 (manual quantification) or 5000 (automated quantification) cells per well were enumerated. The digitized images shown were adjusted for brightness and contrast using ImageJ, without further alteration.

\section{Magnetic-activated cell sorting}

Neuronal/glial cells differentiated for 13 days were detached using Gibco $^{\mathrm{m}}$ TrypLE $^{\mathrm{Tn}}$ Select Enzyme (1X) and 
collected into N2A-NBC medium. After centrifugation at $80 \times g$ for $10 \mathrm{~min}$, cells were either sub-cultured (UnsC) or supplemented with kynurenic acid buffer and sorted according to the manufacturer's instructions using the Microbead Kit (Miltenyi Biotec \#130-095826). In brief, resuspended cells were incubated for 10 min at $4{ }^{\circ} \mathrm{C}$ with $20 \mu \mathrm{l}$ biotin-conjugated anti-GLAST (ACSA-1) antibodies per $10^{7}$ cells, washed, and incubated with anti-biotin MicroBeads for $15 \mathrm{~min}$ at $4{ }^{\circ} \mathrm{C}$. Cell sorting was performed using MS columns (Miltenyi Biotec, \#130-042-201) placed in a MiniMACS ${ }^{\text {st }}$ separator (Miltenyi Biotec \#130-090-312). The cell fractions found in the flow-through or bound to beads were composed of enriched neurons (En-N) and enriched astrocytes (EnAs), respectively. Both sorted and unsorted cells were seeded at a density of 100,000 cells per $\mathrm{cm}^{2}$ on 24-well $\mu$-plates (IBIDI, \#82406) in N2A-NBC or conditioned medium (1:1, fresh N2A-NBC: supernatant of noninfected co-cultures differentiated for 13 days, conditioned for $48 \mathrm{~h}$ ). Conditioned medium allowed neuronal survival in En-N cultures. Half of the medium was replaced every other day.

\section{Statistical analyses}

Data are represented as mean \pm standard deviation (SD). Statistical analyses were performed with GraphPad Prism V4.03 or V6.0.1 using an unpaired Student's $t$ test or a one-way ANOVA analysis (Bonferroni's multiple comparison test), ${ }^{*} p<0.05,{ }^{* * *} p<0.01,{ }^{* * * *} p<0.001$, nonsignificant $(\mathrm{ns})=p>0.05$.

\section{Results}

TBEV infects brain cells differentiated from human fetal neural progenitors

HNPCs and their derived neuronal/glial cells were previously set up in our laboratory for the study of Borna disease virus, a neurotropic virus that belongs to the Bornaviridae family [28, 29]. Here, we used the same hNPCs prepared according to the experimental steps summarized in Fig. 1a. HNPCs were differentiated for 13 days, by which time all neurons were generated [29], before infection with the TBEV-Hypr strain at MOI $10^{-2}$. Infected neuronal/glial co-cultures were then analyzed over time. We first examined the capacity of the virus to infect, replicate, and disseminate within the coculture. Examination of cells immunostained with an antibody specific for domain 3 of the TBEV envelope protein (TBEV-E3), at 24 and $72 \mathrm{~h}$ post-infection (hpi), revealed that TBEV entered human brain cells and spread within the co-culture (Fig. 1b). Enumeration of infected cells from 14 hpi to $7 \mathrm{dpi}$ showed that $7.3 \pm$ $0.7 \%$ of cells were indeed infected at $14 \mathrm{hpi}$, whereas $45.0 \pm 4.0 \%$ were infected at $72 \mathrm{hpi}$, at the peak of infection (Fig. 1c). At a later time, $7 \mathrm{dpi}$, the number of infected cells decreased. A similar pattern of infection was observed when the viral RNA was quantified by RTqPCR, whether in the supernatant or intracellularly, from 14 hpi to 7 dpi (Fig. 1d), with an increase in viral RNA observed up to 48-72 hpi followed by a decrease from 96 hpi to $7 \mathrm{dpi}$. This confirmed active replication of the virus in hNPC-derived brain cells. Quantification of viral titer by endpoint dilution further showed that infectious particles were released into the supernatant and increased from 14 hpi to 48 hpi and 72 hpi (Fig. 1e). Thus, the infection, replication and dissemination of virus were efficient in hNPC-derived neuronal/glial cells.

\section{TBEV infects human neurons, astrocytes, and oligodendrocytes}

We next sought to determine which neural subsets were infected by TBEV in neuronal/glial co-cultures. We had previously shown that, upon growth factor withdrawal, hNPCs differentiated into GABAergic neurons and astrocytes $[28,29]$. Oligodendrocytes, the third cell type that can be generated by differentiation of hNPCs, were not taken into consideration. Of note, microglial cells, which are of mesodermic origin, cannot be generated from fetal neural progenitor cells. To gain in precision, in the present study, we enumerated all 3 cell types, based on immunofluorescence staining (see Additional file 2A), 13 and 21 days after the onset of differentiation. Automatic enumeration of immunostained cells with antibodies directed against $\mathrm{HuC} / \mathrm{HuD}$ (nuclear markers for neurons) and OLIG2 (nuclear marker for oligodendrocytes) revealed a population composed of $77.0 \pm 3.2 \%$ $(\mathrm{d} 13)$ and $74.1 \pm 5.4 \%(\mathrm{~d} 21)$ neurons and $1.4 \pm 1.0 \%(\mathrm{~d} 13)$ and $3.7 \pm 1.0 \%$ (d21) oligodendrocytes (see Additional file 2B). Due to technical limitations (GFAP localization in astrocytic outgrowths and unavailability of a nuclear marker), astrocytes could not be automatically enumerated. The remaining population, namely total cells minus neurons and oligodendrocytes, comprising $21.5 \pm 4.1 \%$ (d13) and $22.2 \pm 4.4 \%$ (d21) of cells, was therefore considered to be composed of astrocytes (see Additional file $2 \mathrm{~B})$. The reliability of this enumeration procedure was confirmed by manual enumeration, as $22.8 \pm 5.6 \%$ (d13) and $32.7 \pm 5.0 \%(\mathrm{~d} 21)$ of astrocytes were found using this method (see Additional file 2C). Thus, we confirmed that neurons and astrocytes were the major cell types in our co-cultures and showed that oligodendrocytes constituted less than $5 \%$ of the total cell population.

To characterize TBEV cellular tropism, we infected hNPC-derived neuronal/glial co-cultures and followed infection from $14 \mathrm{~h}$ to 7 days. Cells were coimmunostained with antibodies directed against TBEVE3 (infected cells) and $\beta$ III-tubulin or $\mathrm{HuC} / \mathrm{HuD}$ (neurons), GFAP (astrocytes) and OLIG2 (oligodendrocytes). At $24 \mathrm{hpi}$, the 3 cell types were infected, as shown in 
Fig. 2a. Viral envelope strongly accumulated in the perinuclear region of the cytoplasm in all cell types. The protein could also be evidenced in certain neurites and astrocyte outgrowths, albeit with a lower intensity (Fig. $2 b)$. We then sought to determine whether the virus spread within each cellular subpopulation. We therefore quantified infection in each cell type, at different time points during the course of the study (Fig. 2c-e). The general profile of infection at onset was similar in the 3 cell types, with an increase in the first days of infection up until a peak occurring at 48-72 hpi. While this phase was followed by a decrease from 96 hpi onwards in the neuronal population, the percentage of infection remained stable in astrocytes and oligodendrocytes, at least up to $7 \mathrm{dpi}$. Early in infection, at $14 \mathrm{hpi}$, a minority of cells were infected within each subset, namely $7.9 \pm$ $1.2 \%$ of neurons, $4.3 \pm 1.5 \%$ of astrocytes, and $11.7 \pm 0.8 \%$ of oligodendrocytes. Later, however, at the peak of infection, the proportion of infected cells was high in neurons $(55.2 \pm 3.8 \%)$ and oligodendrocytes $(68.0 \pm 21.5 \%)$ but much lower in astrocytes $(13.6 \pm 5.3 \%)$, revealing differential propagation of the virus within the three subpopulations. Thus, whereas human neurons and oligodendrocytes were highly susceptible to TBEV infection, human astrocytes were more resistant.

\section{TBEV induces death of neurons and astrocytes}

As hNPC-derived neuronal/glial cells were highly infected, we then sought to evaluate whether TBEV induced cellular damage. Cultures were infected, and cells were fixed at several time points from $14 \mathrm{hpi}$ to $14 \mathrm{dpi}$ before immunostaining with antibodies specific for neuronal and glial cells, as previously described. We first examined the neuronal population. At $14 \mathrm{dpi}$, examination of $\mathrm{HuC} / \mathrm{HuD}$ immunostaining revealed that TBEVinfected co-cultures were strongly depleted in neurons, as compared with their non-infected matched controls (Fig. 3a). Enumeration showed that neuronal survival was unaffected in the first days of infection (from 14 to 48 hpi) but confirmed that neuronal loss occurred as early as 72 hpi $(25.1 \pm 5.4 \%$ loss $)$ and steadily increased from this point on, reaching $72.0 \pm 10.3 \%$ at $14 \mathrm{dpi}$, the latest time point of our study (Fig. 3b). We then examined neuronal morphology based on BIII-tubulin immunostaining. At $7 \mathrm{dpi}$, a striking loss of neurites was observed in TBEV-infected cultures as compared with their non-infected matched controls (Fig. 3c). Quantification of total neurite length confirmed their loss not only at $7 \mathrm{dpi}(76.1 \pm 21.6 \%$ decrease), but also at $72 \mathrm{hpi}$ $(62.0 \pm 22.6 \%$ decrease), whereas they were unaffected at an earlier time point (14 hpi) (Fig. 3d). Of note, whereas neuronal death became progressively more pronounced between $72 \mathrm{hpi}$ and $7 \mathrm{dpi}$, neurite loss was as high at 72 hpi as at $7 \mathrm{dpi}$, suggesting that neurites alteration precedes neuronal death. In an attempt to determine the molecular mechanisms responsible for neuronal loss, we performed TUNEL staining at 24 and $72 \mathrm{hpi}$. Whereas there was no difference at $24 \mathrm{hpi}$, an increase in TUNEL staining was observed at $72 \mathrm{hpi}$ in TBEV-infected cells as compared with their matched non-infected controls (Fig.3e, f), revealing that apoptotic events occurred as early as 72 hpi. Co-immunostaining with anti- $\beta$ IIItubulin antibody further demonstrated that apoptotic cells were neurons (Fig. 3e, right panel). Taken together, these results showed that TBEV infection strongly impaired neuronal survival in the co-cultures and, moreover, suggested that neurite alteration preceded neuronal death. They also explained the decrease in the percentage of infected cells and viral RNA at 7 dpi as shown in Fig. 1c/d. Indeed, as neurons represented the most numerous and highly infected cells, their massive death by that time point would have inevitably diminished the percentage of total infected cells.

We next evaluated whether glial cells were damaged. Examination of astrocytes immunostained with an antibody directed against GFAP at $7 \mathrm{dpi}$ revealed hypertrophic cells in TBEV-infected cultures, as compared with their non-infected matched controls (Fig. 4a). This change in morphology is reminiscent of astrogliosis, a common feature of stressed astrocytes. Enumeration of GFAP-positive cells was then carried out at $24 \mathrm{hpi}, 72$ hpi, and $7 \mathrm{dpi}$. Their number was not significantly altered at the earlier time points, $24 \mathrm{hpi}$ and $72 \mathrm{hpi}$, but a decrease of $20.7 \pm 11.1 \%$ was observed at $7 \mathrm{dpi}$ compared with non-infected matched controls (Fig. 4b). Thus, TBEV infection diminished survival of not only neurons but also astrocytes, although in a more moderate manner for the latter. By contrast, enumeration of OLIG-2positive cells did not reveal a significant difference in oligodendrocyte number in TBEV-infected and noninfected cultures (Fig. 4c), showing that despite direct TBEV infection, survival of oligodendrocytes was unaffected. Taken together, our results demonstrated that subsets of hNPC-derived brain cells, that is, neurons, astrocytes, and oligodendrocytes, were differentially affected by TBEV infection. In particular, neurons were highly susceptible as regards both infection and mortality, whereas astrocytes were more resistant. Oligodendrocytes were susceptible to infection, but their survival was unaffected.

\section{Human NPC-derived neuronal/glial co-cultures develop a strong antiviral response to TBEV infection}

When infected with virus, cells initiate an antiviral response that aims at controlling viral replication. In order to determine whether the human neuronal/glial cells used in our study had conserved the capacity to develop such a response upon TBEV infection, we 


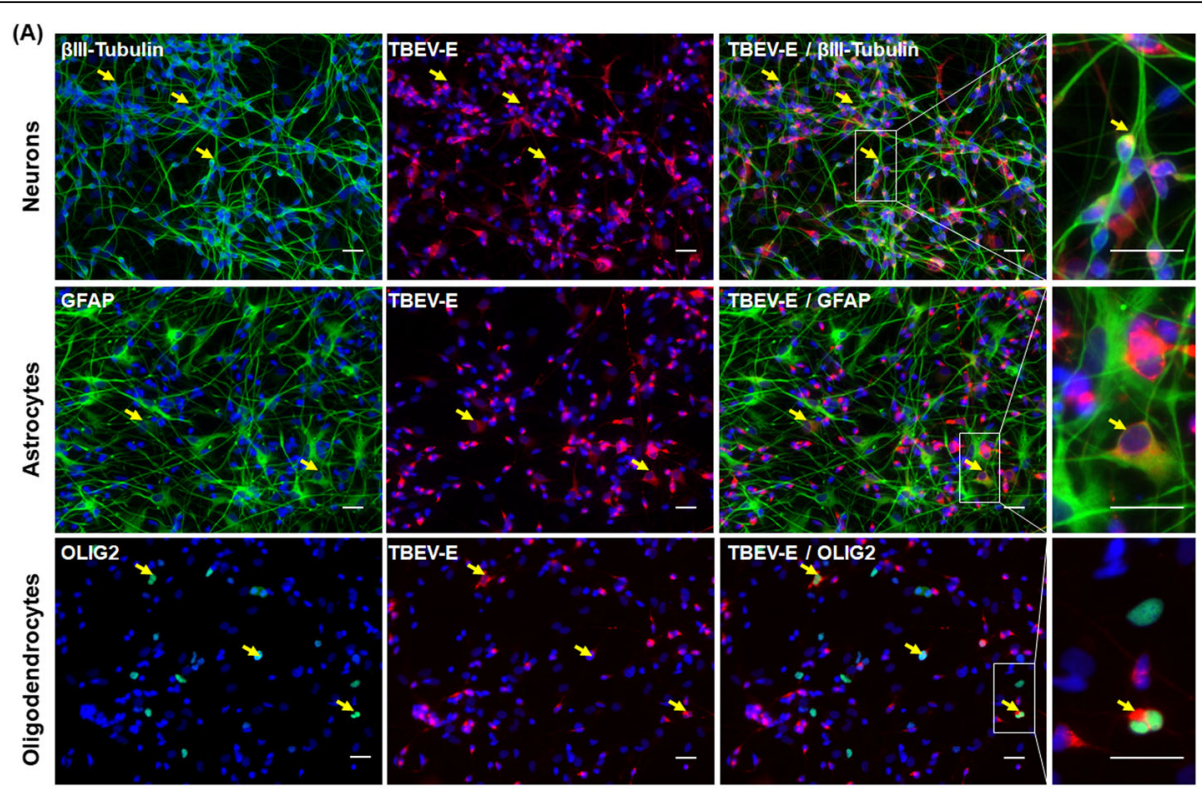

(B)

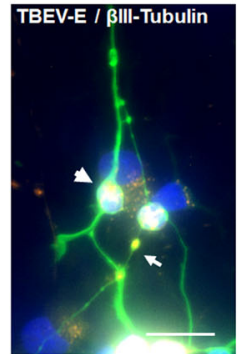

(D)

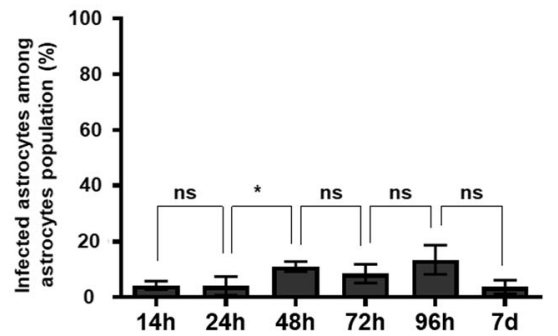

(C)

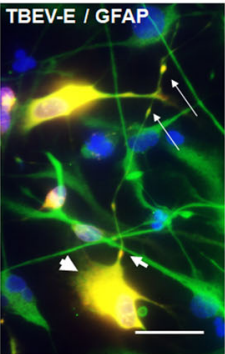

(E)
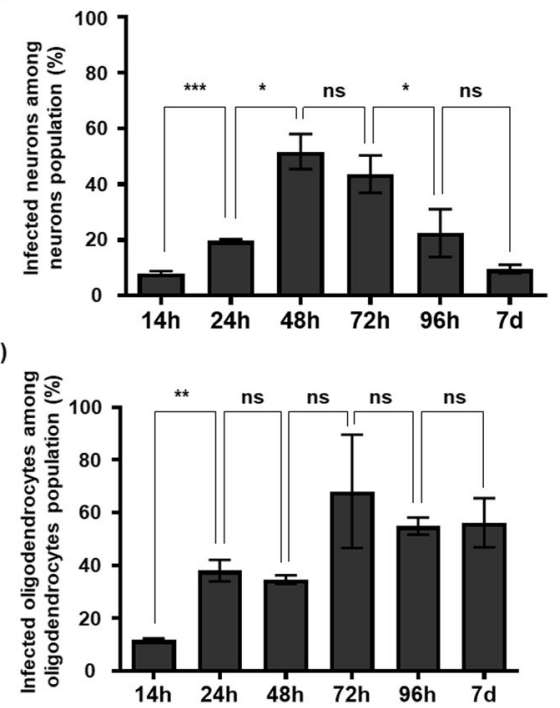

Fig. 2 TBEV tropism for hNPC-derived brain cells. HNPCs differentiated for 13 days were infected with TBEV-Hypr at MOI $10^{-2}$. a Immunofluorescence labeling of infected cells at $24 \mathrm{hpi}$. Antibodies against $\beta$ III-tubulin (neurones), GFAP (astrocytes), or OLIG2 (oligodendrocytes) (green), and TBEV-E3 (red) were used. Nuclei were stained with DAPI (blue). Yellow arrows show infected neurons, astrocytes, and oligodendrocytes. Digital higher magnification is shown in the right panel. Oligodendrocytes were recolored from gray to green. Scale bar $=$ $20 \mu \mathrm{m}$. b Higher magnification (digitally cropped) showing the viral envelope in perinuclear areas (arrowhead) and neurites and astrocytic outgrowths (arrows). Scale bar $=20 \mu \mathrm{m}$. c-e Percentage of infected cells based on immunofluorescence labeling during the course of infection for (c) neurons, (d) astrocytes, and (e) oligodendrocytes. Results are representative of at least 2 independent experiments performed in triplicate. Data are expressed as the mean \pm SD. Statistical analysis was performed using a two-tailed unpaired $t$ test with Graphpad Prism V6.0.1. ns, nonsignificant $(p>0.05)$; ${ }^{*} p<0.05,{ }^{* *} p<0.01,{ }^{* * *} p<0.001$

analyzed the differential expression of 84 human genes involved in the antiviral response, using a PCR array approach. Transcripts from hNPC-derived neuronal/glial cells infected with TBEV for $24 \mathrm{~h}$ were pooled from biological triplicates and compared with transcripts from their matched non-infected controls. The studied genes are shown in Fig. 5a and Additional file 3. After applying an arbitrary cut-off of threefold, 25 genes were shown to be significantly modulated in TBEV-infected cells, among which 22 genes were upregulated and 3 were downregulated (Fig. 5a). The former category included pathogen recognition receptors (PRRs), cytokines, including IFN- $\beta$, and ISGs. Upregulation of nine of these genes, 3 PRRs-IFIH1/MDA5 (Fig. 5b), DDX58/RIG-I (Fig. 5c), and TLR3 (Fig. 5d); 3 pro-inflammatory cytokines- 


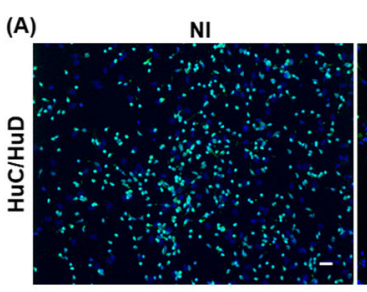

(C)
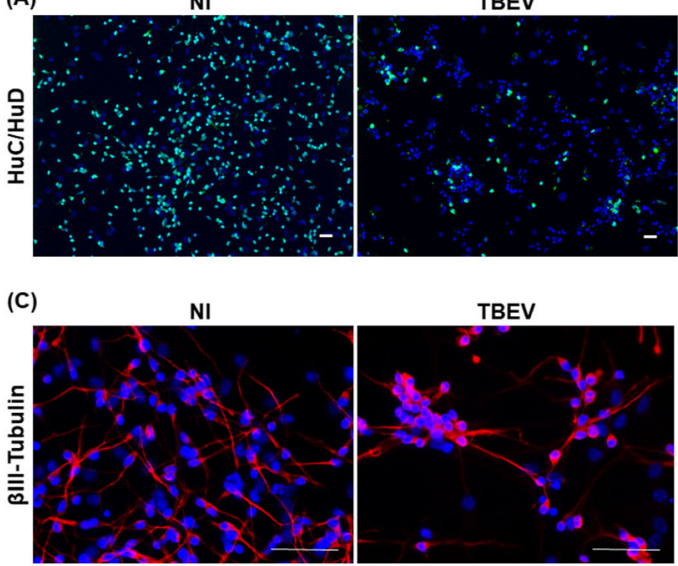

(D)

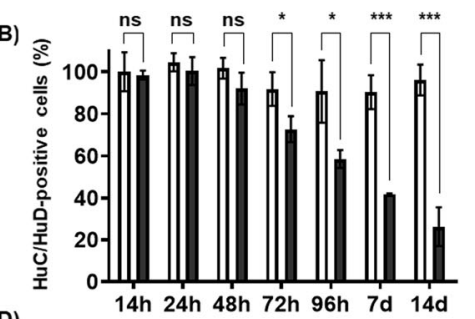

\section{हี}
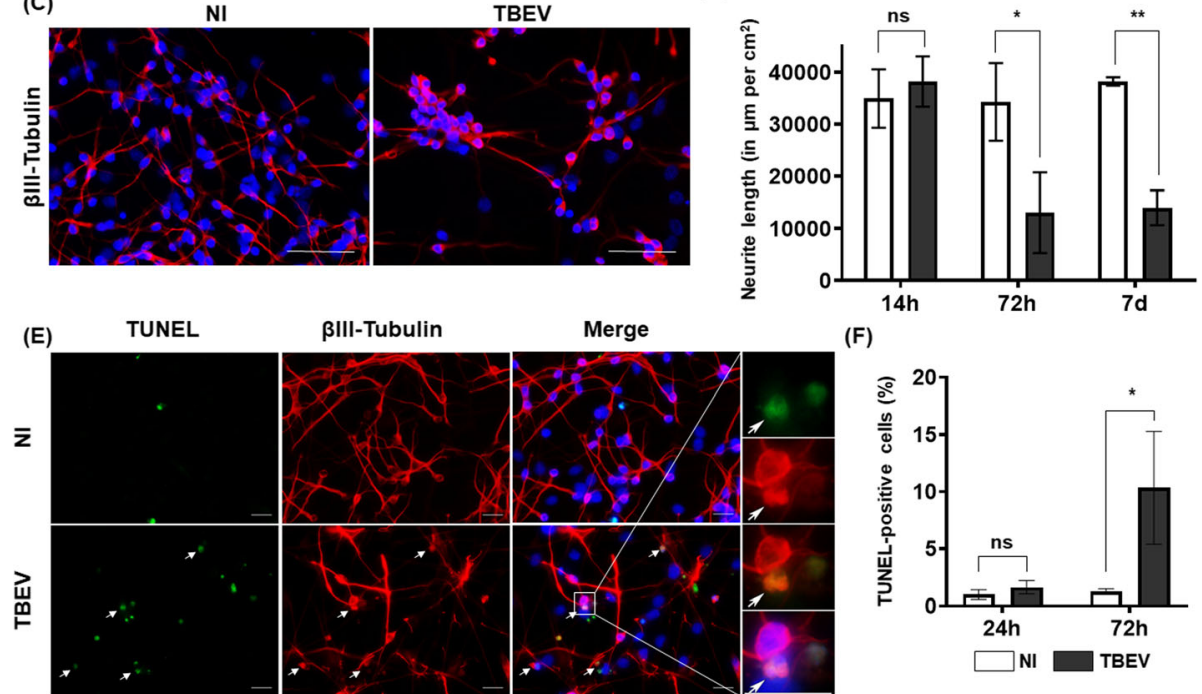

Merge (F)

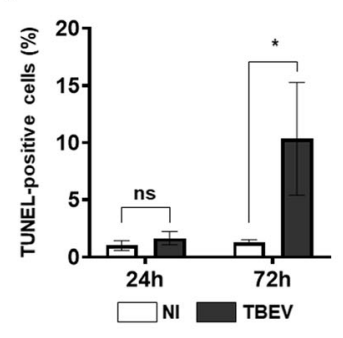

Fig. 3 TBEV damages human neurons. HNPCs were differentiated for 13 days and infected with TBEV-Hypr at MOI 10-2 . a Cells in non-infected (NI) and infected (TBEV) co-cultures were immunostained with an antibody directed against HuC/HuD (neurons, green) at 14 dpi. Nuclei were counterstained with DAPI. Scale bars $=100 \mu \mathrm{m}$. b Enumeration of HuC/HuD-positive cells using an ArrayScan Cellomics instrument. Normalization to non-infected HuC/HuD-positive cells at 14 hpi. c Cells in non-infected and infected cultures were immunostained with an antibody against $\beta$ IIItubulin (neurons, red) at $7 \mathrm{dpi}$. Note the paucity of neurites in TBEV-infected co-cultures. Scale bars $=100 \mu \mathrm{m}$. $\mathbf{d}$ Quantification of neurite network density (neurite length per square millimeter) using an ArrayScan Cellomics instrument. e Cells in non-infected and TBEV-infected cultures were TUNEL stained at 72 hpi. Note that TUNEL staining matches with $\beta$ Ill-tubulin immunostaining (arrows). Right panel show an apoptotic neuron (co-localization of Blll-tubulin and TUNEL staining). Scale bars $=20 \mu \mathrm{m}$. (f) Percentage of apoptotic cells based on TUNEL staining at 24 and $72 \mathrm{hpi}$. Results in $\mathbf{b}, \mathbf{d}$, and $\mathbf{f}$ are expressed as the mean \pm SD and are representative of four $(\mathbf{b})$ and two $(\mathbf{d}, \mathbf{f})$ independent experiments performed in triplicate, respectively. Statistical analysis was performed using a two-tailed unpaired $t$ test with Graphpad Prism V6.0.1. ns, non-significant $(p>$ $0.05) ;{ }^{*} p<0.05,{ }^{* *} p<0.01,{ }^{* * *} p<0.001$

CXCL10 (Fig. 5e), CCL5/RANTES (Fig. 5f), and CXCL11 (Fig. 5g); and 3 ISGs-OAS2 (Fig. 5h), MX1 (Fig.5i), and ISG15 (Fig. 5j), was confirmed using RTqPCR. IFI6 (Fig. 5k), an additional ISG that was recently shown to protect cells from Flavivirus infection [34], was also shown to be upregulated. For most of these genes, kinetic analyses further revealed that their expression was activated as early as $7 \mathrm{hpi}$ and progressively increased during the course of infection up to $14 \mathrm{dpi}$, with the exception of pro-inflammatory cytokines whose expression abruptly decreased at 14 dpi (Fig. 5e-g). The latter, however, remained highly upregulated, as compared with their matched noninfected controls. These data indicated that TBEVinfected hNPC-derived neuronal/glial cells had the capacity to respond to TBEV infection by developing a strong and lasting antiviral response.

\section{Differential antiviral response in human neurons and} human astrocytes

Neurons and astrocytes are both known to participate in the antiviral response in the CNS [20,35]. As regards oligodendrocytes, little is known so far [36]. Our results, showing high susceptibility of neurons but resistance of astrocytes to TBEV infection, led us to hypothesize that differences in their intrinsic capacity for antiviral defense might underlie their differential susceptibility. In order to test this hypothesis and decipher cell-autonomous anti-TBEV innate immunity in the human CNS, we sought to obtain cultures enriched in neurons (henceforth called En-N) or astrocytes (henceforth called EnAs) and to compare their antiviral response. Oligodendrocytes were not considered further in this study, as their low number in our cultures precluded enrichment. After differentiation of hNPCs for 13 days, neuronal/glial 
(A)

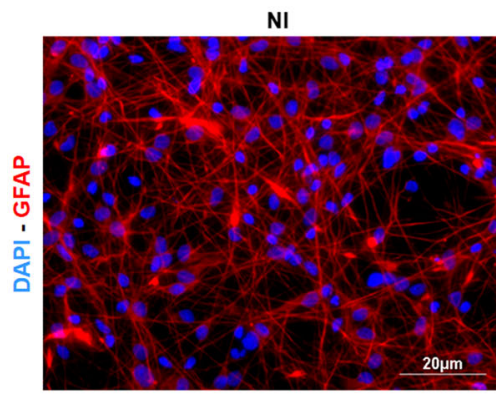

(B)

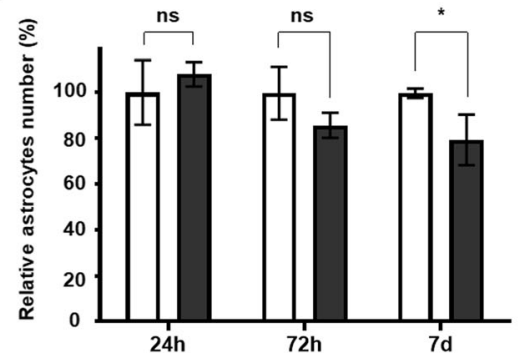

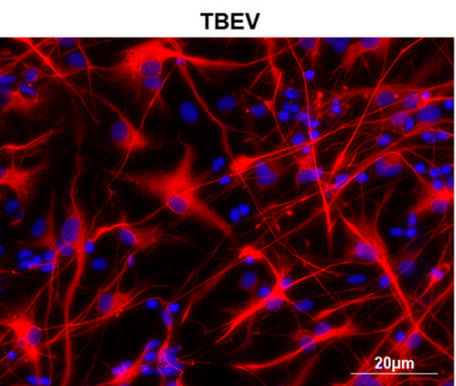

(C)

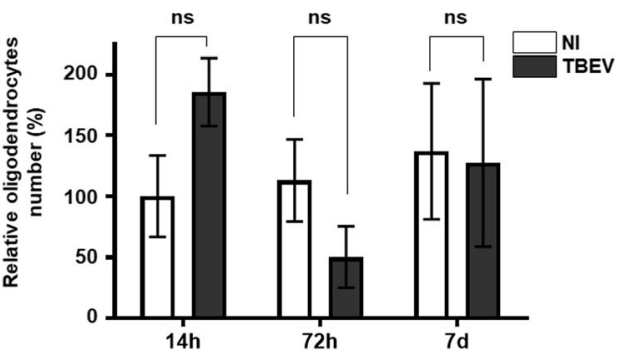

Fig. 4 Impact of TBEV on human glial cells. HNPCs were differentiated for 13 days and infected with TBEV-Hypr at MOI 10-2. a Cells in noninfected (NI) and infected (TBEV) co-cultures were immunostained with an antibody directed against GFAP (astrocytes, red) at 7 dpi. Nuclei were counterstained with DAPI. Scale bars $=20 \mu \mathrm{m}$. b Manual enumeration of GFAP-positive cells using ImageJ software. Normalization was performed relative to non-infected GFAP-positive cells at 24 hpi. c Cells immunostained with OLIG2 antibody were enumerated automatically. Normalization was performed relative to non-infected OLIG2-positive cells at 24 hpi. The results are expressed as the mean \pm SD and are representative of two (oligodendrocytes) and three (astrocytes) independent experiments performed in triplicate. Statistical analysis was performed using a two-tailed unpaired $t$ test with Graphpad Prism V6.0.1. ns, non-significant $(p>0.05)$; ${ }^{*}<0.05$

cells were trypsinized and either directly re-seeded (unsorted cultures henceforth called Uns-C) or enriched for neurons (En-N) or astrocytes (En-As). We showed that the splitting procedure did not alter the neuronal/glial co-cultures (Uns-C). Indeed, 4 days after re-seeding, phase-contrast microscopy of Uns-C revealed typical neuronal (small sized with neurites) and astroglial (larger, flat, with outgrowths) cells (Fig. 6a), as typically observed in non-trypsinized co-cultures (henceforth called $\mathrm{Co}-\mathrm{C}$ cells). Immunofluorescence staining using antibodies directed against neurons $(\mathrm{HuC} / \mathrm{HuD})$, astrocytes (GFAP), and oligodendrocytes (OLIG2) markers showed a mixed population (Fig. 6b) composed of $74.1 \pm 4.1 \%$ neurons, $20.8 \pm 4.9 \%$ astrocytes, and $5.1 \pm 1.2 \%$ oligodendrocytes (Fig. 6c) revealing that the percentage of each subpopulation was unchanged in Uns-C as compared with Co-C cells. Basal expression of antiviral genes was also unchanged, as shown by the analysis of 84 genes of the antiviral response in Uns- $\mathrm{C}$ and $\mathrm{Co}-\mathrm{C}$ cells (Fig. 6d). Enrichment in neurons and in astrocytes was confirmed by phase-contrast microscopy (Fig. 6e and h, respectively) and immunofluorescence staining (Fig. $6 \mathrm{f}$ and i, respectively) combined with cell enumeration showing that the En-N population was composed of $94.1 \pm 0.4 \%$ neurons, $3.1 \pm 0.4 \%$ astrocytes and $2.8 \pm 0.2 \%$ oligodendrocytes (Fig. 6g) while the En-As population comprised
$53.5 \pm 2.7 \%$ astrocytes, $35.7 \pm 2.8 \%$ neurons, and $10.8 \pm$ $0.5 \%$ oligodendrocytes (Fig. $6 \mathrm{j}$ ).

We then sought to determine whether distinct antiviral responses occurred in En-As, En-N, and Uns-C upon TBEV infection, which would reflect differential antiviral responses in human neurons and astrocytes. Cells were infected for $24 \mathrm{~h}$, and the expression of 84 genes of the antiviral response was compared using the same PCR array as previously described. After application of the usual arbitrary cut-off of threefold, 20 genes in TBEV-infected Uns-C, 16 genes in TBEV-infected En$\mathrm{N}$ and 21 genes in TBEV-infected En-As were shown to be significantly upregulated, as compared with their non-infected matched controls (Fig. 7a and Additional file 4). Among the set of upregulated genes, which overlapped with that of non-trypsinized cocultures, 13 were common to the three cultures (Table 1) while others were specific for En-As or En-N cultures ( $8 / 21$ and $3 / 16$, respectively). Thus, these results showed that the antiviral program activated by TBEV was partially different in human neurons and astrocytes. Of note, for $12 / 13$ of common genes, the magnitude of upregulation was correlated to the percentage of astrocytes in the cultures. That is, it was much higher in En-As than in En-N and intermediary in Uns-C (Fig. 7a, Table 1 ), showing that human astrocytes were capable of 


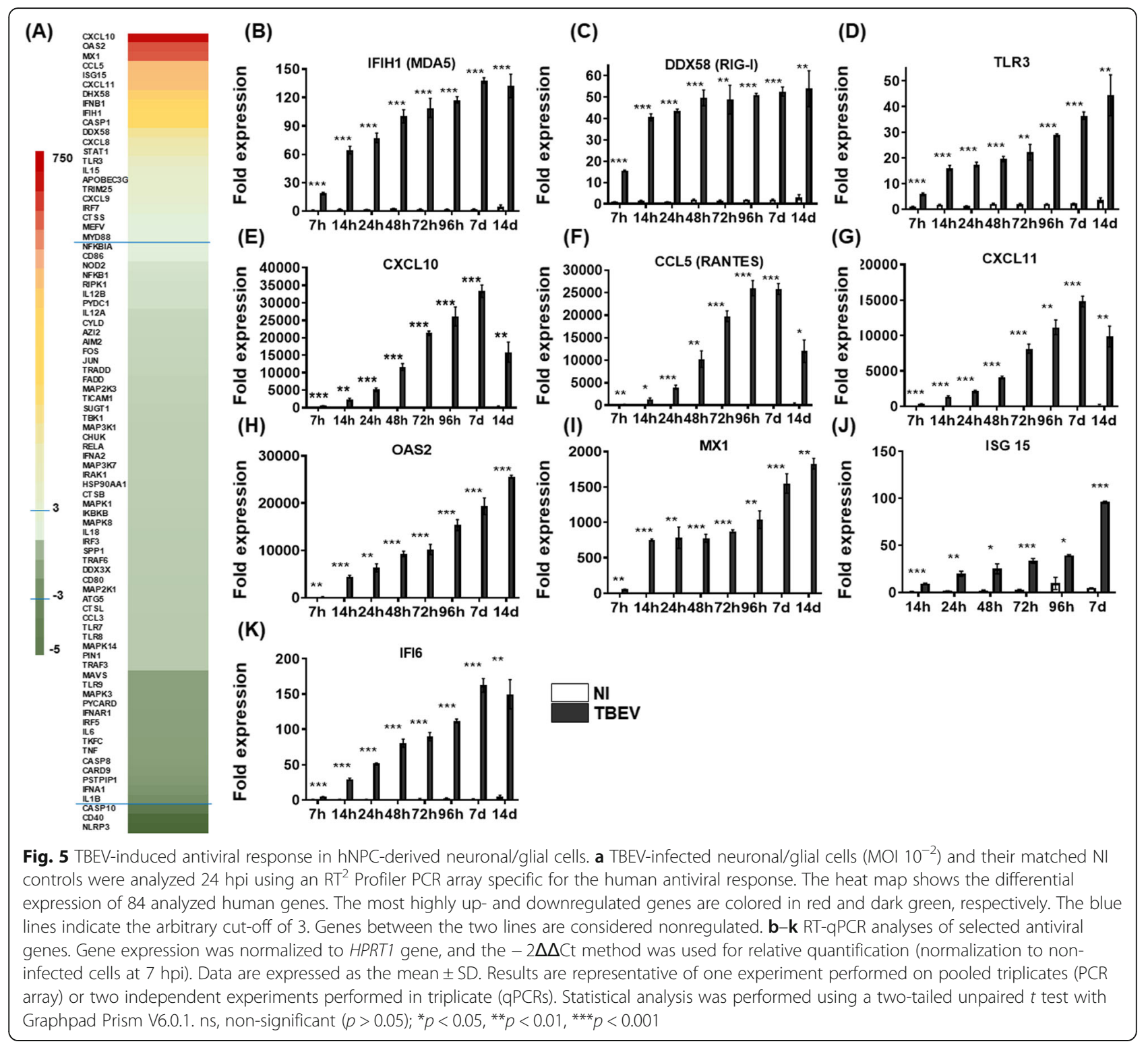

developing a stronger antiviral response to TBEV than human neurons. To validate the PCR array data and to gain further insight into the kinetics of expression of antiviral genes in each cell types, we performed RTqPCR at 7, 24, and 72 hpi for IFN- $\beta$, (Fig. 7b), 3 PRRsIFIH1 (MDA5) (Fig. 7c), DDX58 (RIG-I) (Fig. 7d), and TLR3 (Fig. 7e); two ISGs-OAS2 (Fig. 7f) and MX1 (Fig. $7 \mathrm{~g}$ ); and one pro-inflammatory cytokine-CXCL10 (Fig. 7h). Because of their well-known anti-flavivirus activity, the ISGs IFI6 (Fig. 7i), RSAD2 (viperin) (Fig. 7j), and TRIM5 $\alpha$ (Fig.7k) were also studied. In confirmation of the PCR array data, all of these genes were significantly more upregulated in En-As than in En-N, at both 24 and $72 \mathrm{hpi}$. In addition, at $72 \mathrm{hpi}$, gene expression in En-N was either maintained (RIG-I, TLR3, OAS2, viperin, CXCL10, TRIM5 $\alpha$, IFN- $\beta$ ) or decreased (MDA5,
MX1, IFI6), while it was either maintained (MDA5, TLR3, MX1, viperin, TRIM5 $\alpha$, IFN- $\beta$ ) or increased (RIG-I, OAS2, CXCL10, IFI6) in En-As, showing that the duration of antiviral responses was shorter in human neurons than in astrocytes. The induction of an astrocyte-specific antiviral program, as suggested by the selective upregulation of 8 genes in En-As (Fig. 7a, Table 1 ), was further confirmed by the results of RT-qPCR. Not only TLR3 but also viperin and TRIM5 $\alpha$ were among those genes, as upregulation was observed in EnAs at 24 hpi and 72 hpi but not in En-N at either time point (Fig. 7e, j, k). Thus, taken together, these results show that TBEV infection induces an antiviral response in human neurons and astrocytes that is characterized by activation of an overlapping set of genes. This antiviral program, however, was of greater intensity and 


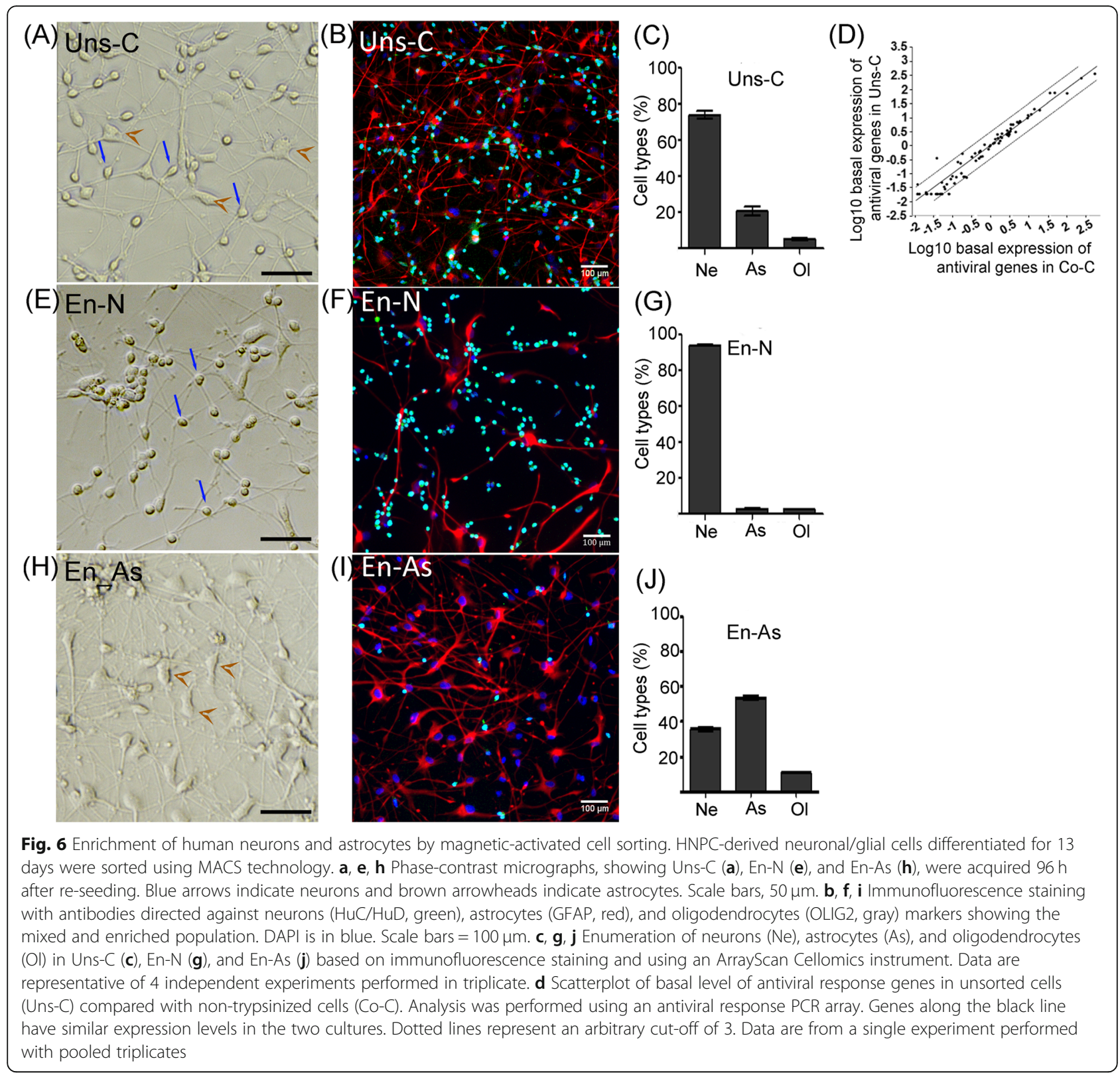

longer duration in human astrocytes than in human neurons. The antiviral programs of the two cell types were also notably distinct, as exemplified by selective upregulation of the genes encoding viperin and TRIM $5 \alpha$, well-known for their anti-TBEV and anti-flavivirus activities [37-39], in human astrocytes. In sum, our results revealed a stronger and broader antiviral response in human astrocytes than in human neurons, in keeping with their differential susceptibility to TBEV infection, astrocytes being more resistant and neurons more susceptible.

Differential expression of antiviral genes in human neurons and astrocytes following TBEV infection may reflect differential baseline expression in the two cell types. To test this hypothesis, non-infected En-N, Uns-C, and En-As cells were cultured for 4 days and transcripts from 3 biological samples in each condition were pooled and compared using the human antiviral response PCR array. Antiviral gene expression in En-N was compared with that of Uns-C (Fig. 7l) and En-As (Fig. 7m). Although in both cases, most of the immunity-related genes were not differentially expressed to a significant extent (above the threefold threshold recommended by the manufacturer), we observed that the general tendency was to a slight overexpression in astrocytes, since the number of significantly overexpressed genes increased as the percentage of astrocytes increased in the culture, from 


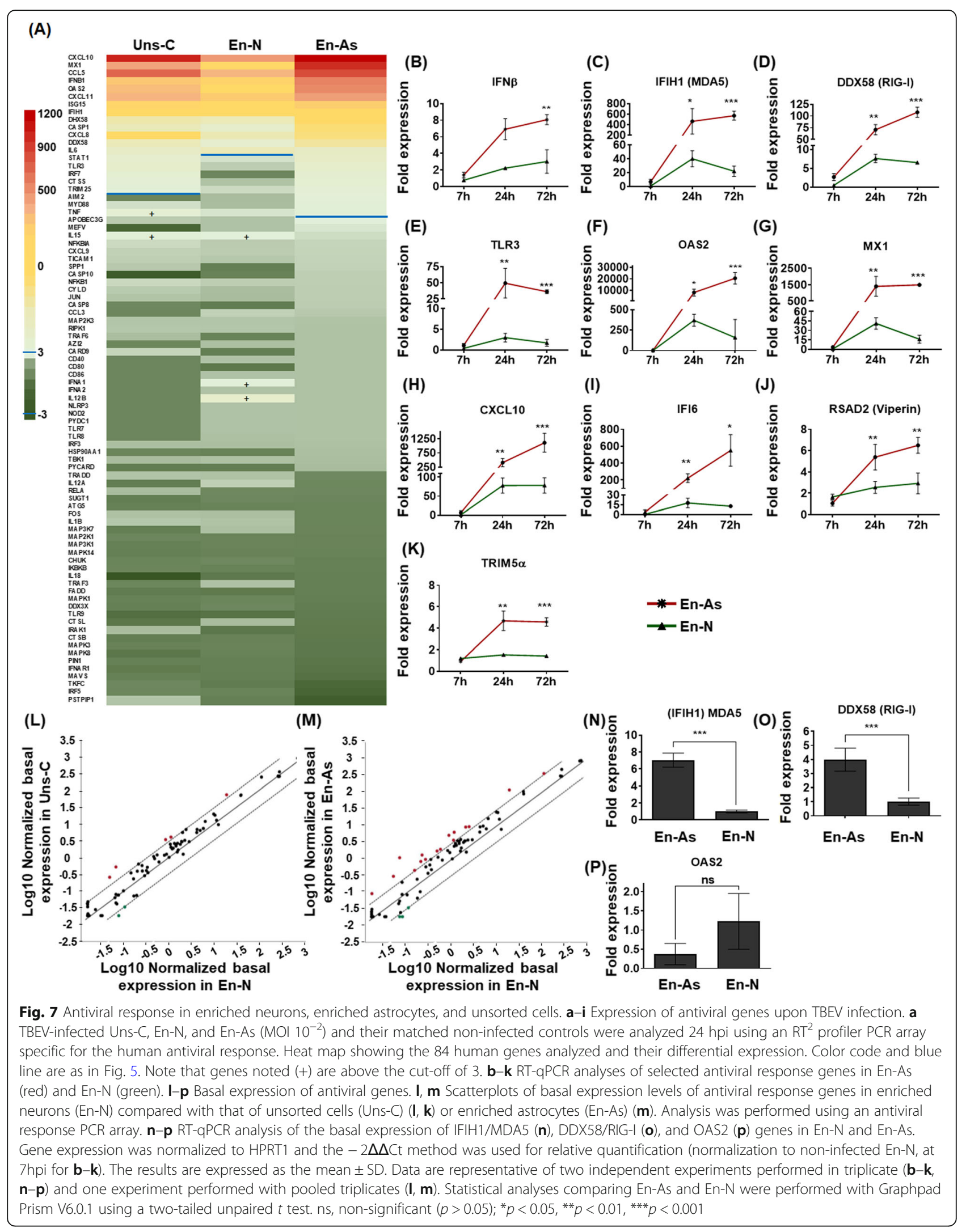


Table 1 Differential expression of genes involved in the human antiviral response in unsorted cultures (Uns-C), enriched neurons (En-N), and enriched astrocytes (En-As). Up- and downregulated genes appear in bold, after application of a cutoff of 3

\begin{tabular}{|c|c|c|c|}
\hline \multirow{2}{*}{$\begin{array}{l}\text { Gene } \\
\text { name }\end{array}$} & \multicolumn{3}{|c|}{ Fold regulation } \\
\hline & Uns-C & En-Ne & En-As \\
\hline CXCL10 & 1024.0 & 415.9 & 1209.3 \\
\hline MX1 & 367.1 & 39.1 & 975.5 \\
\hline CCL5 & 680.3 & 265.0 & 814.6 \\
\hline IFNB1 & 149.1 & 71.5 & 537.5 \\
\hline OAS2 & 215.3 & 23.9 & 498.0 \\
\hline CXCL11 & 270.6 & 126.2 & 388.0 \\
\hline ISG15 & 61.8 & 31.8 & 105.4 \\
\hline $\mathrm{IF|H} 1$ & 32.7 & 19.7 & 35.3 \\
\hline DHX58 & 13.2 & 10.6 & 28.2 \\
\hline CASP1 & 10.5 & 6.3 & 24.6 \\
\hline CXCL8 & 28.4 & 11.4 & 23.1 \\
\hline DDX58 & 10.5 & 5.7 & 16.0 \\
\hline IL6 & 7.4 & 10.6 & 8.2 \\
\hline STAT1 & 5.8 & 2.5 & 7.5 \\
\hline TLR3 & 6.2 & 1.7 & 6.4 \\
\hline IRF7 & 5.0 & 0.9 & 5.3 \\
\hline CTSS & 4.3 & 1.3 & 5.2 \\
\hline TRIM25 & 3.6 & 2.2 & 4.5 \\
\hline AlM2 & 0.9 & 1.0 & 4.0 \\
\hline MYD88 & 2.4 & 1.1 & 3.7 \\
\hline TNF & 4.5 & 2.6 & 3.7 \\
\hline IL15 & 3.8 & 3.3 & 2.3 \\
\hline IFNA1 & 0.9 & 3.6 & 1.2 \\
\hline IL12B & 0.9 & 5.9 & 1.2 \\
\hline
\end{tabular}

Uns-C to En-A. Five/84 genes were, indeed, overexpressed in Uns-C compared with En-N (Fig. 61), while their number rose to 14/84 genes when En-As were compared with En-N (Fig. 6m). By contrast, very few of these genes (3/84) were overexpressed in human neurons, and then only to a modest extent. To validate these results, differential expression of 3 selected genes, 2 PRRs (MDA5 and RIG-I) and 1 ISG (OAS2), was further addressed by RT-qPCR. Significant overexpression of MDA5 (Fig. 7n) and RIG-I (Fig. 7o) in En-As as compared with En-N was confirmed. By contrast, but still in agreement with the PCR array data, no significant difference was observed for the OAS2 gene (Fig. 7p). These results thus showed that the basal level of expression of certain antiviral genes was higher, albeit slightly, in human astrocytes than in human neurons.
Human astrocytes protected human neurons from TBEV infection and TBEV-induced damage

Next, we wondered whether human astrocytes might participate in neuronal defense. We reasoned that, if this were the case, neurons would be more sensitive to TBEV infection in cultures depleted of astrocytes. We therefore compared neuronal susceptibility and vulnerability to TBEV infection in Uns-C and En-N, composed of $20.8 \pm$ $4.9 \%$ and $3.1 \pm 0.4 \%$ of astrocytes, respectively. Uns-C and En-N were infected for $24 \mathrm{~h}$, and the percentage of TBEV-infected neurons within the total neuronal population was quantified based on BIII-tubulin and TBEVE3 immunostaining. A 30\% increase in infected cells was observed in En-N compared with Uns-C (Fig. 8a), showing that, in the absence of astrocytes, neurons were more sensitive to TBEV infection. At that time, neuronal survival was altered neither in TBEV-infected Uns-C nor in TBEV-infected En-N, as revealed by observation of BIIItubulin immunostaining (Fig. 8b) and enumeration of neurons (see Additional file 5). At $72 \mathrm{hpi}$, however, a more dramatic alteration of neuronal morphology was observed in TBEV-infected En-N, as compact clusters, characteristic of intense neuronal death, were formed (Fig. 8b). Due to these clusters, it was not possible to enumerate the neurons, but our results clearly showed that, at $72 \mathrm{hpi}$, neurons were more dramatically affected in cultures deprived of astrocytes. Thus, taken together, these results showed that, upon TBEV infection, the presence of astrocytes was protective for human neurons.

\section{Discussion}

Despite its importance in human health, TBEV-induced neuropathogenesis is still poorly understood. So far, most studies have used either in vitro or in vivo rodent models, whereas these models have advanced understanding, extrapolation to human neuropathogenesis may not always be relevant, as cellular responses display profound differences between species [25, 26, 40]. Here we used neuronal/glial cultures derived from human fetal neural progenitor cells as a more accurate in vitro model to study anti-TBEV innate immunity and its relation to tropism and neuropathogenesis in the human brain. We developed a new in vitro model that mimics major hallmarks of TBEV infection in the human brain, namely neuronal tropism, neuronal death, and astrogliosis, thereby providing a unique and highly relevant pathological model for studying TBEV-induced neuropathogenesis. Moreover, we revealed that a cell typespecific innate antiviral state in human neurons and astrocytes correlates with their differential susceptibility and vulnerability to TBEV, which strongly suggests that the innate antiviral response shapes TBEV tropism for human brain cells. 


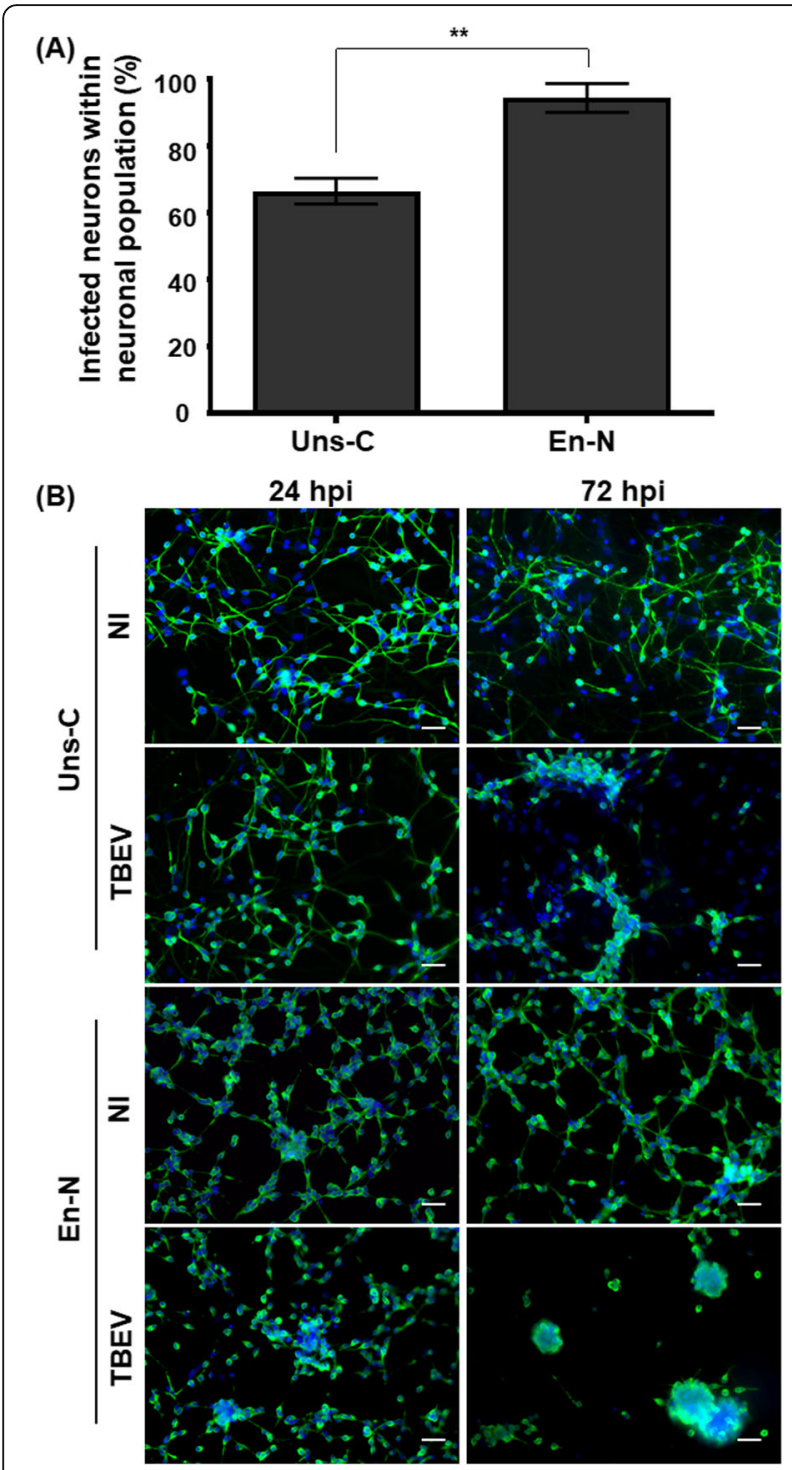

Fig. 8 Human astrocytes protect neurons from TBEV infection. Unsorted cells (Uns-C) and enriched neurons (En-N) were infected with TBEV (MOI 10 ${ }^{-2}$ ) and co-immunostained using anti-Blll-tubulin and anti-TBEV-E3 antibodies. a Percentage of infected neurons among the neuronal population. Manual enumeration. Data are expressed as the mean \pm SD. $\mathbf{b}$ Immunofluorescence staining of neurons (green). Nuclei were stained with DAPI (blue). Scale bar = $20 \mu \mathrm{m}$. Results are representative of two independent experiments performed in triplicate. Statistical analyses were performed with Graphpad Prism V6.0.1 using a two-tailed unpaired $t$ test, ${ }^{* *} p<0.01$

Understanding viral tropism is critical for understanding virus-induced neuropathogenesis. Some viruses, like Zika virus, preferentially infect neural progenitors [41, 42], whereas human immunodeficiency virus has a strong affinity for microglial cells [43], JC virus for astrocytes [44] and the JHM strain of mouse hepatitis virus (JHMV) for oligodendrocytes [45]. Flaviviruses such as TBEV, WNV, and JEV have a preferential tropism for neurons, a feature that has been observed in human patients [12, 46, 47], as well as in rodent models [48, 49]. Using human neuronal/glial cultures, we reproduced the preferential neuronal tropism that is observed in vivo in showing a high percentage of infected neurons (approximately $55 \%$ at the peak of infection) together with a low percentage of infected astrocytes (less than 15\%). The limited capacity of the virus to infect astrocytes, as observed in our cultures, as well as in monocultures of rodent or human astrocytes [50-52], may explain the lack of detection of infected astrocytes in post-mortem brain tissues from patients with tick-borne encephalitis [12], or their rare detection in Langat virus-infected mice [49], as infrequently infected cells are likely to escape detection. Similar observations have been made for other neurotropic viruses [53-55]. Unexpectedly, we also observed infection of oligodendrocytes in the human neuronal/glial cultures, a finding that has never been reported previously. The in vivo significance of this observation is at present unknown, especially because the degree of maturation of oligodendrocytes in our culture is undefined, the OLIG2 antibody recognizing mature and immature cells indiscriminately [56]. However, this should be kept in mind for future examination of brain tissues from infected patients. As these cells represent about $5 \%$ of the total cell population in our cultures, we believe them to have a minor impact in vitro and, as we could not enrich them, they were not further considered and we confined our study to neurons and astrocytes. We questioned the reasons that may explain the difference in TBEV tropism for these two cell types. This may be due to differential expression of cellular factors that are necessary for establishing a full viral cycle (entry and post-entry events), but the similar percentage of infected neurons and astrocytes that we observed in the first $14 \mathrm{~h}$ following TBEV infection does not lend support for this hypothesis. An alternative hypothesis would be differential capacity of the cell types to develop a protective antiviral response. The innate immune response, a major component of the antiviral response, has indeed been proven to be critically important in restricting infection by neurotropic viruses [57-59] and in determining TBEV tropism in different brain areas in murine models $[49,60]$. Also, studies using rodent models have shown that distinct brain cell types develop different antiviral states. Microglia and astrocytes, for example, which were initially considered to be the sole sentinels that respond to microbial infection within the brain $[61,62]$ have been shown to behave differently, as microglia developed a more robust response than astrocytes to TLR7 activation [63]. Neurons, long considered to be merely passive targets, are now known to participate in the antiviral response and viral restriction [19-21, 64], and in humans, neurons and astrocytes have been shown to produce and 
respond to IFN- $\alpha / \beta$. Despite a general assumption that astrocytes are more important players in antiviral response than neurons, the relative contribution of each cell type has, however, not been formally demonstrated, as a direct comparison has never been made, whether in animal or in human in vitro models. Here, we provide the first evidence that human neurons derived from fetal neural progenitor cells possess all of the necessary machinery to mount a cell-intrinsic antiviral response against TBEV, as they upregulated IFN- $\beta$, ISGs, and proinflammatory cytokine mRNAs upon TBEV infection. We also demonstrated for the first time that human neurons and astrocytes differ in their capacity to mount an anti-TBEV response. Differences were indeed observed in the repertoire of the antiviral program that is activated in the two cell types upon TBEV infection, with certain genes upregulated in astrocytes but not in neurons, such as the RSAD2 (encoding viperin) and TRIM5 $\alpha$ genes, two ISGs that have been shown to be highly important for controlling TBEV [37, 38] and other flaviviruses $[39,60]$ in the rodent's CNS. Quantitative differences were also observed as transcripts encoding PRRs and genes of IFN signaling were upregulated with different magnitudes in human neurons and astrocytes, with a stronger and more durable response in astrocytes than in neurons. Our results thus show that the cell type-specific anti-TBEV response is correlated with the susceptibility of human neurons and astrocytes to TBEV, which strongly suggests that the innate antiviral response is responsible for shaping TBEV tropism in human brain cells. Such role of innate antiviral response was previously shown for TBEV and other flaviviruses in different neuronal sub-types of murine origin $[19,60]$. Whether the high neuronal susceptibility to TBEV infection in the human neuronal/glial cultures is due to a weaker general antiviral program in human neurons, involving multiple components of the IFN response, from the PRRs to ISGs, or rather to lower expression of specific ISGs, such as the RSAD2, IFI6, and TRIM $5 \alpha$ genes, that are dedicated to the control of flaviviruses [30], remains to be elucidated. It also remains to be determined whether the antiviral response of neurons is weak in response to infection by any neurotropic virus, or only by certain viruses, such as flaviviruses, or whether it is specific to TBEV infection. Our observation that the baseline expression of certain antiviral genes is lower in neurons than in astrocytes may argue in favor of the first possibility, a hypothesis that should be addressed in future studies. In contrast to our results, TBEV infection in the human neuronal DAOY cells, a human neuroblastoma, led to upregulation of the RSAD2 gene [65], a discrepancy that may be due to the use of nonphysiological, immortalized cells in the study in question. Of note, our results showed that neuronal tropism of TBEV does not depend only on the cell-specific antiviral response in human neurons, as the presence of astrocytes in the culture limited their infection and favored their survival. As it was previously reported that murine astrocytes infected with TBEV were protective to neurons through IFN signaling [50], and as we showed that IFN $\beta$ was highly upregulated by human astrocytes upon TBEV infection, we speculate that IFN $\beta$ produced by astrocytes acts in a paracrine manner to restrict neuronal infection in our human neuronal/glial co-cultures. However, it cannot be ruled out that other yet unknown factors may be involved.

Viral tropism and pathogenesis are intimately linked, but how the former governs the latter in the human CNS, during TBEV infection, is incompletely understood. TBEV preferentially infects and kills the neurons [12], a highly dramatic event, as neurons have a very poor capacity to regenerate. Neuronal death may occur in either direct or indirect manners, such as, in the latter case, by inducing secretion of neurotoxic proteins by resident glial cells or recruitment of peripheral inflammatory cells to the brain parenchyma $[11,14]$. Involvement of $\mathrm{T}$ cells in neuronal death cannot be explored in our model. However, it should be noted that chemokines such as CXCL10, CCL5, and CXCL11, which have been shown to be overexpressed in the cerebrospinal fluid of human patients infected with TBEV [66-68], are highly upregulated by both human neurons and astrocytes, revealing that the two cell types may participate in chemo-attraction of $\mathrm{T}$ cells into TBEV-infected human brain parenchyma. Similar to the observation made for PRRs and ISGs, their upregulation was, however, stronger in astrocytes than in neurons, showing that astrocytes may be a major player in this process as well. Regarding neuronal death due to direct infection by TBEV, it has not yet been demonstrated, although ultrastructural changes in response to TBEV infection have been observed [69, 70]. In our human neuronal/glial and enriched neuron cultures, neuronal death occurred in the absence of peripheral cells and was associated with infection of a large proportion of neurons, showing that the virus is directly responsible for their death. This is likely to play an important role in the human brain upon infection with TBEV and most probably other flaviviruses, since similar conclusions have been drawn for West Nile virus in studies performed in primary murine neurons [71]. Reactive astrocytes, however, may also influence neuronal death. Astrogliosis, indeed, occurs following brain trauma of diverse etiology [72], including infection by TBEV or the related Langat virus infection [12], and may be either beneficial or detrimental to neurons [73]. In human neuronal/glial 
cultures, we have observed that astrocytes were hypertrophic, a classical feature of reactive astrocytes and, when neurons were deprived of astrocytes, they were more sensitive to TBEV infection, showing that astrocytes exerted, under these conditions, a neuroprotective effect, possibly via restriction of neuronal infection as previously discussed. Thus, the intensity of neuronal death depends not only on direct infection of neurons but also on the indirect effect mediated by reactive astrocytes. Proliferation sometimes accompanied astrocyte hypertrophy in astrogliosis. Surprisingly, in our experiments, we observed a decrease in the number of astrocytes by 7 days following infection, which strongly suggested that TBEV induced astrocytic death. This is in apparent contradiction with previous work showing that astrocyte viability was unaffected in rodent and human astrocyte monocultures $[51,52]$. The difference in our results may be due to differential conditions of infection, such as viral strain or infectious dose or to the presence of neurons in our co-cultures, which may lead to astrocyte death by an unknown mechanism. Of note, infection with TBEV is not always correlated to cell death, since as many as $60 \%$ of oligodendrocytes were infected without impact on their viability. Why certain cell types die upon TBEV infection while others do not remains to be understood, as do the molecular pathways that lead to cell death. Interestingly, our findings suggest that neuronal death may result from axonal pathology and retrograde degeneration. Indeed, we showed that loss of neurites preceded the disappearance of neuronal cell bodies, an observation that is in agreement with previous work in which accumulation of viral protein in neuritic extensions and dendritic degeneration due to local replication of TBEV was evidenced in murine neurons [69]. The relative contribution of axonal degeneration, which is known to play a pathogenic role in rabies virus infection [74] and in some neurodegenerative diseases [75], to TBEV-induced neuronal death need to be defined in future studies.

\section{Conclusions}

Until recently, the lack of relevant in vitro models virtually precluded meaningful study of viral pathogenesis in the human brain. This obstacle has been overcome by the development of methodologies providing an unlimited source of human neural cell types that can be used for disease modeling. In this study, we set up a new, complex, and highly relevant in vitro model that mimics the major events of TBEV infection in the human brain. Using this model, we evidenced differential innate immune responses in human neurons and astrocytes that contribute to shaping TBEV tropism and

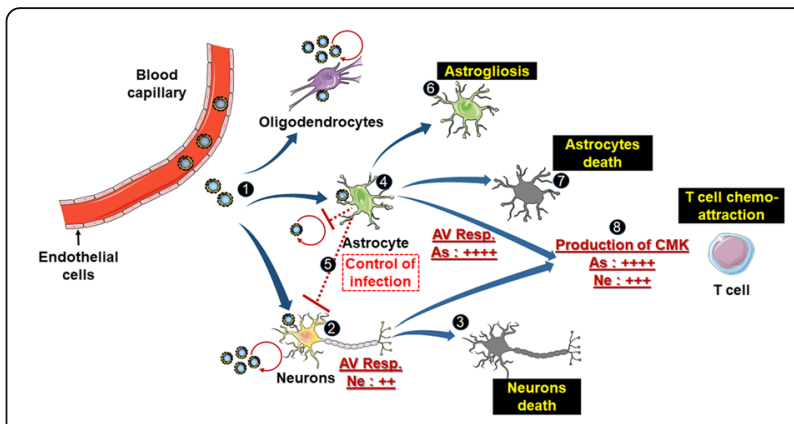

Fig. 9 Proposed model of interactions between TBEV and human brain cells. In the human brain parenchyma, TBEV infects neurons, astrocytes, and possibly oligodendrocytes (1). Both neurons and astrocytes develop an antiviral response. In neurons, it is insufficient to afford protection (2) and poorly controlled infection induces neuronal death in a direct manner (3). Astrocytes are infected but control infection, owing to their strong antiviral response (4), which may also be beneficial to neurons (5). Astrocytes enter a reactive stage (6) and some of them die (7). Both neurons and astrocytes overexpressed a high level of chemokines involved in chemoattraction of T cells in the brain parenchyma (8), although astrocytes are stronger producers. The figure was created using Servier Medical Art available on www.servier.com. As, astrocytes; AV Resp, antiviral response; CMK, chemokines; $\mathrm{Ne}$, neurons

neuropathogenesis. Based on our results, we propose a model for interactions between TBEV and human brain cells that is represented in Fig. 9. Our study thus advances understanding of the mechanisms involved in TBEV-induced damage of the human brain and provides a pathological model that can be used in the future to provide greater knowledge as well as to develop new therapies by screening for antiviral or neuroprotective drugs.

\section{Supplementary information}

Supplementary information accompanies this paper at https://doi.org/10. 1186/s12974-020-01756-X.

\begin{abstract}
Additional file 1. Primer pairs used for qRT-PCR analyses.
Additional file 2. Neurons and astrocytes are the major cell types in hNPCs-derived cultures. HNPCs were differentiated for 13 days. (A) Immunofluorescence labeling using antibodies against $\mathrm{HuC/HuD}$, a neuronal nuclear marker (green), GFAP, an astrocytic marker (red) and OLIG2, an oligodendrocyte nuclear marker (gray) were used. Nuclei were stained with DAPI (blue). Scale bar $=20 \mu \mathrm{m}$. (B) Enumeration of cells based on immunofluorescence labeling. Automated quantification using an ArrayScan Cellomics instrument. (C) Enumeration of astrocytes based on immunofluorescence labeling. Manual quantification.
\end{abstract}

Additional file 3. TBEV-induced antiviral response in neuronal/glial cells (PCR array data, 24 hpi).

Additional file 4. Antiviral response in enriched neurons, astrocytes and unsorted cells (PCR array data, $24 \mathrm{hpi}$ ).

Additional file $\mathbf{5}$ Neuronal survival is not affected by TBEV infection at $24 \mathrm{hpi}$ in unsorted cells and enriched neuron cultures. Unsorted cultures (Uns-C) and enriched neurons (En-N) were infected with TBEV and COimmunostained with $\beta$ III-tubulin (neurons) and anti-TBEV-E3 antibodies. Manual enumeration of infected neurons was performed at $24 \mathrm{hpi}$. Data 
are expressed as the mean + SD and normalized to non-infected Uns-C. Results are representative of two independent experiments performed in triplicate. Statistical analysis was performed using a two-tailed unpaired $t$ test with GraphPad Prism V6.0.1, ns = non-significant ( $p>0.05)$.

\section{Abbreviations}

BSL-3: Bio-safety level-3; CNS: Central nervous system; Co-C: Non-trypsinized co-cultures; d13/d21: Day 13 or 21 after the onset of differentiation; DAPI: 4',6-Diamidino-2-phenylindole; DCs: Dendritic cells; En-As: Enriched astrocytes; En-N: Enriched neurons; hESCs: Human embryonic stem cells; hiPSCs: Human induced pluripotent stem cells; hNPCs: Human neural progenitor cells; hpi: Hours post-infection; IFN: Interferon; IFNAR: IFN alpha/ beta receptor; ISG: Interferon-stimulated genes; JEV: Japanese encephalitis virus; JHMV: JHM strain of mouse hepatitis virus; POWV: Powassan virus: PRRs: Pathogen recognition receptors; TBEV: Tick-borne encephalitis virus; Uns-C: Unsorted sub-cultured cells; WNV: West Nile virus; ZIKV: Zika virus

\section{Acknowledgements}

We are most grateful to Dr. S Moutailler for providing the TBEV-Hypr strain and to K Gorna and F Piumi for their technical help in the revised form of the manuscript We deeply thank Drs. PE Ceccaldi and T Couderc for sharing their insight and Dr. N Jouvenet for critical reading of the manuscript.

\section{Authors' contributions}

MF conceived the study, developed and designed the methodology, carried out most of the experiments, performed the formal analysis, validated the results, and drafted the manuscript. MCB and CB carried out part of the RT$P C R$, immunofluorescence, and cellular enumeration. GG carried out part of the RT-PCR and immunofluorescence and participated in editing the manuscript. $C N M M, O B, A B$, and $S L$ provided resources and participated in editing the manuscript. JR participated in the writing, reviewing, and editing of the manuscript. NH participated in the writing, reviewing, and editing of the manuscript and in the supervision of the project and funding acquisition. MC conceived the study, developed and designed the methodology, validated the results, drafted the manuscript, supervised and administered the project, and acquired the funding. The authors read and approved the final manuscript.

\section{Funding}

This study was financially supported by the French National Institute for Agriculture, Food and the Environment (INRAE) and DIM Mallnf (lle de France). MF was financially supported by a Ph.D. fellowship from INRA and the Paris Institute of Technology for Life, Food, and Environmental Sciences (AgroParisTech). GG was financially supported by Laboratoire d'Excellence Integrative Biology of Emerging Infectious Diseases grant ANR-10-LABX-62IBEID. The funders had no role in study design, data collection and analysis, decision to publish, or preparation of the manuscript.

\section{Availability of data and materials}

Data supporting the conclusions of this work have been presented in the manuscript.

\section{Ethics approval and consent to participate}

Human fetuses were obtained after legal abortion with written informed consent from the patient. The procedure for the procurement and use of human fetal central nervous system tissue was approved and monitored by the "Comité Consultatif de Protection des Personnes dans la Recherche Biomédicale" of Henri Mondor Hospital, France. The cells are declared at the "Centre de Ressources Biologiques" of the University Hospital in Angers BB0033-00038 with reference numbers at the Research Ministry: declaration no. DC-2011-1467 and authorization no. AC-2012-1507.

The rabbit immunization protocol complied with EU legislation (authorization 12/04/11-6 given by the ANSES/ENVA/UPEC ethical committee).

\section{Consent for publication}

Not applicable.

\section{Competing interests}

The authors declare that they have no competing interests.

\section{Author details}

'UMR1161 Virologie, Anses, INRAE, Ecole Nationale Vétérinaire d'Alfort, Université Paris-Est, Maisons-Alfort, France. ${ }^{2}$ MRC-University of Glasgow Centre for Virus Research, Glasgow, Scotland, UK. ${ }^{3}$ CRCINA, UMR 1232 , INSERM, Université de Nantes, Université d'Angers, F-49933 Angers, France. ${ }^{4}$ Centre de Ressources Biologiques, CHU Angers, BB-0033-00038 Angers, France. ${ }^{5}$ CECS, I-STEM, AFM, Evry, France. ${ }^{6}$ UMR BIPAR 956, Anses, INRAE, Ecole Nationale Vétérinaire d'Alfort, Université Paris-Est, Maisons-Alfort, France.

Received: 12 November 2019 Accepted: 21 February 2020 Published online: 03 March 2020

\section{References}

1. Dumpis U, Crook D, Oksi J. Tick-borne encephalitis. Clin Infect Dis Off Publ Infect Dis Soc Am. 1999;28(4):882-90.

2. Růžek D, Dobler G, Donoso MO. Tick-borne encephalitis: pathogenesis and clinical implications. Travel Med Infect Dis. 2010;8(4):223-32.

3. Caracciolo I, Bassetti M, Paladini G, Luzzati R, Santon D, Merelli M, et al. Persistent viremia and urine shedding of tick-borne encephalitis virus in an infected immunosuppressed patient from a new epidemic cluster in NorthEastern Italy. J Clin Virol Off Publ Pan Am Soc Clin Virol. 2015;69:48-51.

4. Heinz FX, Holzmann H, Essl A, Kundi M. Field effectiveness of vaccination against tick-borne encephalitis. Vaccine. 2007:25(43):7559-67.

5. Donoso Mantke O, Escadafal C, Niedrig M, Pfeffer M, Working Group For Tick-Borne Encephalitis Virus C. Tick-borne encephalitis in Europe, 2007 to 2009. Euro Surveill. 2011;16(39). https://doi.org/10.2807/ese.16.39.19976-en.

6. Ruzek D, Avšič Županc T, Borde J, Chrdle A, Eyer L, Karganova G, et al. Tickborne encephalitis in Europe and Russia: review of pathogenesis, clinical features, therapy, and vaccines. Antiviral Res. 2019;164:23-51.

7. Balogh Z, Ferenczi E, Szeles K, Stefanoff P, Gut W, Szomor KN, et al. Tickborne encephalitis outbreak in Hungary due to consumption of raw goat milk. J Virol Methods. 2010;163(2):481-5.

8. Brockmann SO, Oehme R, Buckenmaier T, Beer M, Jeffery-Smith A, Spannenkrebs M, et al. A cluster of two human cases of tick-borne encephalitis (TBE) transmitted by unpasteurised goat milk and cheese in Germany, May 2016. Euro Surveill. 2021;23(15). https://doi.org/10.2807/15607917.ES.2018.23.15.17-00336.

9. Dorko E, Hockicko J, Rimárová K, Bušová A, Popadák P, Popadáková J, et al. Milk outbreaks of tick-borne encephalitis in Slovakia, 2012-2016. Cent Eur J Public Health. 2018;26 Suppl:S47-50.

10. Růžek D, Salát J, Singh SK, Kopecký J. Breakdown of the blood-brain barrier during tick-borne encephalitis in mice is not dependent on CD8+ T-cells. PLoS One. 2011;6(5):e20472.

11. Gelpi E, Preusser M, Laggner U, Garzuly F, Holzmann H, Heinz FX, et al. Inflammatory response in human tick-borne encephalitis: analysis of postmortem brain tissue. J Neurooncol. 2006;12(4):322-7.

12. Gelpi E, Preusser M, Garzuly F, Holzmann H, Heinz FX, Budka H. Visualization of Central European tick-borne encephalitis infection in fatal human cases. J Neuropathol Exp Neurol. 2005;64(6):506-12.

13. Hayasaka D, Nagata N, Fujii Y, Hasegawa H, Sata T, Suzuki R, et al. Mortality following peripheral infection with tick-borne encephalitis virus results from a combination of central nervous system pathology, systemic inflammatory and stress responses. Virology. 2009;390(1):139-50.

14. Růzek D, Salát J, Palus M, Gritsun TS, Gould EA, Dyková I, et al. CD8+ T-cells mediate immunopathology in tick-borne encephalitis. Virology. 2009;384(1): $1-6$.

15. Lazear HM, Pinto AK, Vogt MR, Gale M, Diamond MS. Beta interferon controls West Nile virus infection and pathogenesis in mice. J Virol. 2011; 85(14):7186-94.

16. Stetson DB, Medzhitov R. Antiviral defense: interferons and beyond. J Exp Med. 2006;203(8):1837-41.

17. Takeuchi O, Akira S. Innate immunity to virus infection. Immunol Rev. 2009; 227(1):75-86.

18. González-Navajas JM, Lee J, David M, Raz E. Immunomodulatory functions of type I interferons. Nat Rev Immunol. 2012;12(2):125-35.

19. Cho H, Proll SC, Szretter KJ, Katze MG, Gale M, Diamond MS. Differential innate immune response programs in neuronal subtypes determine susceptibility to infection in the brain by positive-stranded RNA viruses. Nat Med. 2013;19(4):458-64. 
20. Delhaye S, Paul S, Blakqori G, Minet M, Weber F, Staeheli P, et al. Neurons produce type I interferon during viral encephalitis. Proc Natl Acad Sci U S A 2006;103(20):7835-40.

21. Detje CN, Lienenklaus S, Chhatbar C, Spanier J, Prajeeth CK, Soldner C, et al. Upon intranasal vesicular stomatitis virus infection, astrocytes in the olfactory bulb are important interferon beta producers that protect from lethal encephalitis. J Virol. 2015;89(5):2731-8.

22. Hou Y-J, Banerjee R, Thomas B, Nathan C, García-Sastre A, Ding A, et al. SARM is required for neuronal injury and cytokine production in response to central nervous system viral infection. J Immunol Baltim Md 1950. 2013; 191(2):875-83.

23. Schultz KLW, Vernon PS, Griffin DE. Differentiation of neurons restricts arbovirus replication and increases expression of the alpha isoform of IRF-7. J Virol. 2015;89(1):48-60.

24. Weber E, Finsterbusch $K$, Lindquist R, Nair S, Lienenklaus S, Gekara NO, et al. Type I interferon protects mice from fatal neurotropic infection with Langat virus by systemic and local antiviral responses. J Virol. 2014;88(21):12202-12.

25. Mestas J, Hughes CCW. Of mice and not men: differences between mouse and human immunology. J Immunol Baltim Md 1950. 2004;172(5):2731-8.

26. Shaw AE, Hughes J, Gu Q, Behdenna A, Singer JB, Dennis T, et al. Fundamental properties of the mammalian innate immune system revealed by multispecies comparison of type I interferon responses. PLOS Biol. 2017; 15(12):e2004086.

27. Lafaille FG, Ciancanelli MJ, Studer L, Smith G, Notarangelo L, Casanova J-L, et al. Deciphering human cell-autonomous anti-HSV-1 immunity in the central nervous system. Front Immunol. 2015;6:208.

28. Brnic D, Stevanovic V, Cochet M, Agier C, Richardson J, Montero-Menei CN et al. Borna disease virus infects human neural progenitor cells and impairs neurogenesis. J Virol. 2012;86(5):2512-22.

29. Scordel C, Huttin A, Cochet-Bernoin M, Szelechowski M, Poulet A, Richardson J, et al. Borna disease virus phosphoprotein impairs the developmental program controlling neurogenesis and reduces human GABAergic neurogenesis. PLoS Pathog. 2015;11(4):e1004859.

30. Wallner G, Mandl CW, Ecker M, Holzmann H, Stiasny K, Kunz C, et al. Characterization and complete genome sequences of high- and lowvirulence variants of tick-borne encephalitis virus. J Gen Virol. 1996;77(Pt 5): 1035-42.

31. Livak KJ, Schmittgen TD. Analysis of relative gene expression data using real-time quantitative PCR and the $2^{-\Delta \Lambda C T}$ method. Methods. 2001;25(4): 402-8.

32. Schwaiger M, Cassinotti P. Development of a quantitative real-time RT-PCR assay with internal control for the laboratory detection of tick borne encephalitis virus (TBEV) RNA. J Clin Virol. 2003;27:136-45. https://doi.org/10. 1016/S1386-6532(02)00168-3.

33. Beck C, Desprès P, Paulous S, Vanhomwegen J, Lowenski S, Nowotny N, et al. A high-performance multiplex immunoassay for Serodiagnosis of Flavivirus-associated neurological diseases in horses. Biomed Res Int. 2015; 2015:678084.

34. Richardson RB, Ohlson MB, Eitson JL, Kumar A, McDougal MB, Boys IN, et al. A CRISPR screen identifies IFI6 as an ER-resident interferon effector that blocks flavivirus replication. Nat Microbiol. 2018:3(11):1214-23.

35. Farina C, Aloisi F, Meinl E. Astrocytes are active players in cerebral innate immunity. Trends Immunol. 2007;28(3):138-45.

36. Bsibsi M, Ravid R, Gveric D, van Noort JM. Broad expression of toll-like receptors in the human central nervous system. J Neuropathol Exp Neurol. 2002;61(11):1013-21.

37. Panayiotou C, Lindqvist R, Kurhade C, Vonderstein K, Pasto J, Edlund K, et al. Viperin restricts Zika virus and tick-borne encephalitis virus replication by targeting NS3 for proteasomal degradation. J Virol. 2018;92(7):e02054-17.

38. Upadhyay AS, Vonderstein K, Pichlmair A, Stehling O, Bennett KL, Dobler G, et al. Viperin is an iron-sulfur protein that inhibits genome synthesis of tickborne encephalitis virus via radical SAM domain activity. Cell Microbiol. 2014;16(6):834-48

39. Chiramel Al, Meyerson NR, McNally KL, Broeckel RM, Montoya VR, MéndezSolís $\mathrm{O}$, et al. TRIM5a restricts Flavivirus replication by targeting the viral protease for proteasomal degradation. Cell Rep. 2019;27(11):3269-3283.e6.

40. Lin C-C, Wu Y-J, Heimrich B, Schwemmle M. Absence of a robust innate immune response in rat neurons facilitates persistent infection of Borna disease virus in neuronal tissue. Cell Mol Life Sci CMLS. 2013;70(22):4399410.
41. Ferraris P, Cochet M, Hamel R, Gladwyn-Ng I, Alfano C, Diop F, et al. Zika virus differentially infects human neural progenitor cells according to thei state of differentiation and dysregulates neurogenesis through the Notch pathway. Emerg Microbes Infect. 2019;8(1):1003-16.

42. Retallack H, Di Lullo E, Arias C, Knopp KA, Laurie MT, Sandoval-Espinosa C, et al. Zika virus cell tropism in the developing human brain and inhibition by azithromycin. Proc Natl Acad Sci U S A. 2016;113(50):14408-13.

43. Cosenza MA, Zhao M-L, Si Q, Lee SC. Human brain parenchymal microglia express CD14 and CD45 and are productively infected by HIV-1 in HIV-1 encephalitis. Brain Pathol Zurich Switz. 2002;12(4):442-55.

44. Aksamit AJ, Sever JL, Major EO. Progressive multifocal leukoencephalopathy: $J C$ virus detection by in situ hybridization compared with immunohistochemistry. Neurology. 1986;36(4):499-504.

45. Kapil P, Butchi NB, Stohlman SA, Bergmann CC. Oligodendroglia are limited in type I interferon induction and responsiveness in vivo. Glia. 2012:60(10): 1555-66.

46. Guarner J, Shieh W-J, Hunter S, Paddock CD, Morken T, Campbell GL, et al. Clinicopathologic study and laboratory diagnosis of 23 cases with West Nile virus encephalomyelitis. Hum Pathol. 2004;35(8):983-90.

47. Iwasaki Y, Zhao JX, Yamamoto T, Konno H. Immunohistochemical demonstration of viral antigens in Japanese encephalitis. Acta Neuropathol (Berl). 1986;70(1):79-81.

48. Kimura-Kuroda J, Ichikawa M, Ogata A, Nagashima K, Yasui K. Specific tropism of Japanese encephalitis virus for developing neurons in primary rat brain culture. Arch Virol. 1993;130(3-4):477-84

49. Kurhade C, Zegenhagen L, Weber E, Nair S, Michaelsen-Preusse K, Spanier J, et al. Type I interferon response in olfactory bulb, the site of tick-borne flavivirus accumulation, is primarily regulated by IPS-1. J Neuroinflammation. 2016;13:22.

50. Lindqvist R, Mundt F, Gilthorpe JD, Wölfel S, Gekara NO, Kröger A, et al. Fast type I interferon response protects astrocytes from flavivirus infection and virus-induced cytopathic effects. J Neuroinflammation. 2016;13(1):277.

51. Palus M, Bílý T, Elsterová J, Langhansová H, Salát J, Vancová M, et al. Infection and injury of human astrocytes by tick-borne encephalitis virus. J Gen Virol. 2014;95(Pt 11):2411-26.

52. Potokar M, Korva M, Jorgačevski J, Avšič-Županc T, Zorec R. Tick-borne encephalitis virus infects rat astrocytes but does not affect their viability. PLoS One. 2014:9(1):e86219.

53. Desai A, Shankar SK, Ravi V, Chandramuki A, Gourie-Devi M. Japanese encephalitis virus antigen in the human brain and its topographic distribution. Acta Neuropathol (Berl). 1995;89(4):368-73.

54. German AC, Myint KSA, Mai NTH, Pomeroy I, Phu NH, Tzartos J, et al. A preliminary neuropathological study of Japanese encephalitis in humans and a mouse model. Trans R Soc Trop Med Hyg. 2006;100(12):1135-45.

55. Sips GJ, Wilschut J, Smit JM. Neuroinvasive flavivirus infections. Rev Med Virol. 2012;22(2):69-87.

56. Yokoo H, Nobusawa S, Takebayashi H, Ikenaka K, Isoda K, Kamiya M, et al. Anti-human Olig2 antibody as a useful immunohistochemical marker of normal oligodendrocytes and gliomas. Am J Pathol. 2004;164(5):1717-25.

57. Durrant DM, Ghosh S, Klein RS. The olfactory bulb: an immunosensory effector organ during neurotropic viral infections. ACS Chem Nerosci. 2016; 7(4):464-9.

58. Lucas-Hourani $M$, Munier-Lehmann $H$, Helynck $O$, Komarova A, Desprès $P$, Tangy $F$, et al. High-throughput screening for broad-spectrum chemical inhibitors of RNA viruses. J Vis Exp JoVE. 2014;(87):51222. https://doi.org/10. 3791/51222.

59. Welsch JC, Charvet B, Dussurgey S, Allatif O, Aurine N, Horvat B, et al. Type I interferon receptor signaling drives selective permissiveness of astrocytes and microglia to measles virus during brain infection. J Virol. 2019;93(13). https://doi.org/10.1128/JVI.00618-19.

60. Lindqvist R, Överby AK. The role of viperin in antiflavivirus responses. DNA Cell Biol. 2018;37(9):725-30.

61. Dong Y, Benveniste EN. Immune function of astrocytes. Glia. 2001;36(2):180 90.

62. Hanisch U-K. Microglia as a source and target of cytokines. Glia. 2002;40(2): 140-55.

63. Madeddu S, Woods TA, Mukherjee P, Sturdevant D, Butchi NB, Peterson KE. Identification of glial activation markers by comparison of transcriptome changes between astrocytes and microglia following innate immune stimulation. PLoS One. 2015;10(7):e0127336. 
64. Chakraborty S, Nazmi A, Dutta K, Basu A. Neurons under viral attack: victims or warriors? Neurochem Int. 2010;56(6-7):727-35.

65. Selinger M, Wilkie GS, Tong L, Gu Q, Schnettler E, Grubhoffer L, et al. Analysis of tick-borne encephalitis virus-induced host responses in human cells of neuronal origin and interferon-mediated protection. J Gen Virol. 2017;98(8):2043-60.

66. Grygorczuk S, Zajkowska J, Swierzbińska R, Pancewicz S, Kondrusik M, Hermanowska-Szpakowicz T. Concentration of the beta-chemokine CCL5 (RANTES) in cerebrospinal fluid in patients with tick-borne encephalitis. Neurol Neurochir Pol. 2006;40(2):106-11.

67. Lepej SZ, Misić-Majerus L, Jeren T, Rode OD, Remenar A, Sporec V, et al, Chemokines CXCL10 and CXCL11 in the cerebrospinal fluid of patients with tick-borne encephalitis. Acta Neurol Scand. 2007;115(2):109-14.

68. Zajkowska J, Moniuszko-Malinowska A, Pancewicz SA, Muszyńska-Mazur A, Kondrusik M, Grygorczuk S, et al. Evaluation of CXCL10, CXCL11, CXCL12 and CXCL13 chemokines in serum and cerebrospinal fluid in patients with tick borne encephalitis (TBE). Adv Med Sci. 2011;56(2):311-7.

69. Hirano M, Yoshii K, Sakai M, Hasebe R, Ichii O, Kariwa H. Tick-borne flaviviruses alter membrane structure and replicate in dendrites of primary mouse neuronal cultures. J Gen Virol. 2014;95(Pt 4):849-61.

70. Bílý T, Palus M, Eyer L, Elsterová J, Vancová M, Rǔžek D. Electron tomography analysis of tick-borne encephalitis virus infection in human neurons. Sci Rep. 2015;5:10745.

71. Shrestha B, Gottlieb D, Diamond MS. Infection and injury of neurons by West Nile encephalitis virus. J Virol. 2003;77(24):13203-13.

72. Liddelow SA, Barres BA. Reactive astrocytes: production, function, and therapeutic potential. Immunity. 2017;46(6):957-67.

73. Soung A, Klein RS. Viral encephalitis and neurologic diseases: focus on astrocytes. Trends Mol Med. 2018;24(11):950-62.

74. Li X-Q, Sarmento L, Fu ZF. Degeneration of neuronal processes after infection with pathogenic, but not attenuated, rabies viruses. J Virol. 2005; 79(15):10063-8,

75. Li J-Y, Conforti L. Axonopathy in Huntington's disease. Exp Neurol. 2013;246: 62-71.

\section{Publisher's Note}

Springer Nature remains neutral with regard to jurisdictional claims in published maps and institutional affiliations.

Ready to submit your research? Choose BMC and benefit from:

- fast, convenient online submission

- thorough peer review by experienced researchers in your field

- rapid publication on acceptance

- support for research data, including large and complex data types

- gold Open Access which fosters wider collaboration and increased citations

- maximum visibility for your research: over $100 \mathrm{M}$ website views per year

At $\mathrm{BMC}$, research is always in progress.

Learn more biomedcentral.com/submissions 